\title{
Current strategies against persistent human papillomavirus infection (Review)
}

\author{
YU LIU*, HONGYI LI*, RUYU PI, YANG YANG, XIA ZHAO and XIAORONG QI \\ Department of Gynecology and Obstetrics, Development and Related Diseases of Women and Children \\ Key Laboratory of Sichuan Province, Key Laboratory of Birth Defects and Related Diseases of Women and Children, \\ Ministry of Education, West China Second Hospital, Sichuan University, Chengdu, Sichuan 610041, P.R. China
}

Received March 25, 2019; Accepted July 16, 2019

DOI: 10.3892/ijo.2019.4847

\begin{abstract}
Human papillomavirus (HPV) is the most common sexually transmitted infection, exhibiting a tropism for the epidermis and mucosae. The link between persistent HPV infection and malignancies involving the anogenital tract as well as the head and neck has been well-established, and it is estimated that HPV-related cancers involving various anatomical sites account for $4.5 \%$ of all human cancers. Current prophylactic vaccines against HPV have enabled the prevention of associated malignancies. However, the sizeable population base of current infection in whom prophylactic vaccines are not applicable, certain high-risk HPV types not included in vaccines, and the vast susceptible population in developing countries who do not have access to the costly prophylactic vaccines, put forward an imperative need for effective therapies targeting persistent infection. In this article, the life cycle of HPV, the mechanisms facilitating HPV evasion of recognition and clearance by the host immune system, and the promising therapeutic strategies currently under investigation, particularly antiviral drugs and therapeutic vaccines, are reviewed.
\end{abstract}

\section{Contents}

1. Introduction

2. HPV-associated diseases

Correspondence to: Dr Xiaorong Qi, Department of Gynecology and Obstetrics, Development and Related Diseases of Women and Children Key Laboratory of Sichuan Province, Key Laboratory of Birth Defects and Related Diseases of Women and Children, Ministry of Education, West China Second Hospital, Sichuan University, 20 South Renmin Road, Block 3, Chengdu, Sichuan 610041, P.R. China

E-mail: qxr3522@126.com

*Contributed equally

Key words: human papillomavirus, persistent infection, antiviral drugs, therapeutic vaccines, immunomodulators
3. HPV life cycle

4. Immune evasion

5. Chemical antivirals

6. Therapeutic vaccines

7. Immunomodulators

8. Future prospects

\section{Introduction}

Human papillomaviruses (HPVs) are a family of non-enveloped viruses with cutaneous and mucosal tropism, causing the most common sexually transmitted disease (1). The association of HPV infections, particularly persistent infections, with a series of malignancies has been well-established, exemplified by anogenital (cervical, vulvar, vaginal, penile and anal) cancer, head and neck cancer (oropharyngeal squamous cell carcinoma affecting the tonsils, tonsillar fossa, tongue, base of the tongue and soft palate), non-melanoma skin cancer in patients with epidermodysplasia verruciformis (EV), and malignant progression of recurrent respiratory papillomatosis (2). These malignancies generally account for $\sim 4.5 \%$ of all cancers (3), among which cervical cancer is a major concern. It is estimated that $\sim 530,000$ new cases and 275,000 deaths from cervical cancer occur annually worldwide, causing a major global disease burden and loss of life years, particularly in developing countries (4-6).

Over the past decades, with the elucidation of the natural history of HPV and HPV-associated diseases, as well as technical progress, effective screening strategies and robust prophylactic vaccines have been developed. As the most groundbreaking scientific discovery in the fight against cervical cancer, prophylactic vaccines have an excellent safety and efficacy profile, conferring type-specific immunity against HPV infection (7). Prophylactic vaccines are virus-like particles (VLP) self-assembled by L1 capsid without viral genome, which trigger neutralizing antibody production, thus blocking the adherence and internalization of HPV by basal cells in the epithelium. These vaccines appear to be a promising approach to decreasing the morbidity and mortality of HPV-associated benign and malignant diseases.

However, despite the prophylactic effect of currently available vaccines, they are not effective in eradicating pre-existing HPV 
infection and associated lesions. In addition, these vaccines merely induce immunity specific to certain HPV types, but are unable to fend off other types of the virus; furthermore, their immunization longevity, which is presumably not lifelong, has yet to be evaluated. Finally, the inaccessibility to vaccines and screening programs in resource-poor regions exposes local populations to a high risk of HPV-associated malignancies, which have already been proven to be responsible for a substantial proportion of the worldwide cancer burden. These unresolved issues necessitate screening programs and further exploration of therapeutic modalities for persistent HPV infection and associated lesions.

However, given the fact that most HPV infections that are accompanied by simultaneous epithelial dysplasia undergo spontaneous clearance under immunological surveillance within 1-2 years (8), not all HPV infections require treatment. Therefore, it is advisable to differentiate persistent HPV infection from transient infection through biomarkers or lesion characteristics, which, unfortunately, have not yet been fully elucidated. What is currently known is that higher-grade lesions have a lower probability of spontaneous regression, and the process of oncogenesis, from low-grade squamous intraepithelial lesion (LSIL) through high-grade squamous intraepithelial lesion (HSIL) to invasive cervical cancer (ICC), is consecutive. Hence, a wait-and-watch approach is usually adopted for patients with LSIL to determine whether there is spontaneous regression or progression, while HSIL is mostly treated by physical ablative or surgical modalities (9). Such strategies are practicable, but cannot address the anxiety of patients with LSIL during the long wait, or exclude the possibility of LSIL progression. Furthermore, the currently available therapeutic modalities, primarily surgical treatment, are somewhat destructive and costly, and are characterized by a high recurrence rate, several side effects and complications, restricting their applicability in LSIL management. Therefore, there is a need for non-invasive interventions, such as medications, that are appropriate for both LSIL and HSIL, or even ICC, as well as transformation of the overall concept from treating cancer to treating infection.

The aim of this review article was to discuss the extensive previous and ongoing investigations into antiviral agents, therapeutic vaccines and immunomodulators, along with their respective advantages and drawbacks.

\section{HPV-associated diseases}

A certain group of diseases were demonstrated to be associated with HPV infection; these may be divided into benign and malignant lesions, according to their prognosis, or into mucosal and cutaneous lesions, according to their primary location. Specifically, mucosal and cutaneous lesions in anogenital sites resulting from HPV infection are classified together into one category due to their similar natural history and etiological relevance. Hence, HPV-associated diseases may be classified as anogenital, aerodigestive and non-genital cutaneous infections.

All HPV-associated diseases share dysplasia of the epithelium as the common pathological characteristic. In particular, dysplasia of the stratified squamous epithelium in anogenital sites is further classified into grade 1, 2 and 3 intraepithelial neoplasia, corresponding to mild, moderate and severe dysplasia, respectively, with grade 3 intraepithelial neoplasia also representing carcinoma in situ. The term LISL in cytopathology is equivalent to grade 1 intraepithelial neoplasia and HSIL refers to grade 2 and 3 intraepithelial neoplasia.

HPV infection in anogenital sites. Although most HPV infections in anogenital sites, regardless of the HPV type, result in low-grade dysplasia, which may take the form of a benign condylomatous lesion highly likely to regress spontaneously within 2 years (10), persistent infection with high-risk HPV types has been recognized as a strong carcinogenic factor.

The role of high-risk HPV infection as a prerequisite for cervical cancer development has been well established due to the work of Boshart et al $(11,12)$. It is believed that almost all cervical cancer cases are caused by HPV, and that HPV-negative cases were misclassified due to the limitation of testing methods (false-negative) (13). HPV-16 is the most frequent type found in cervical cancer, followed by HPV-18, $-45,-31,-33$ and other high-risk types (14). HPV-18 is more common in adenocarcinoma compared with squamous cell carcinoma, while adenocarcinoma accounts for $\sim 10 \%$ of all cervical cancer cases (15). As regards low-risk HPV types, such as HPV-6 and -11, they are mostly found in low-grade lesions, such as cervical intraepithelial neoplasia (CIN)1, but are rarely found in high-grade lesions (CIN 2, 3 and ICC).

Anal cancer ranks second in terms of correlation with HPV infection. A study in France reported that $97 \%$ of the cases of anal cancer are HPV-positive, most of which are HPV-16-positive (16). Similarly, it is estimated that $70 \%$ cases of vaginal cancer, $45 \%$ cases of penile cancer and $40 \%$ cases of vulvar cancer are attributed to HPV, particularly HPV-16 (17). Anal intraepithelial neoplasia (AIN), vaginal intraepithelial neoplasia (VAIN), penile intraepithelial neoplasia (PIN) and vulvar intraepithelial neoplasia (VIN) are deemed as precursors of the respective carcinomas, with a certain risk of progression $(18,19)$.

HPV infection in the aerodigestive tract. Low-risk HPVs, mainly HPV-6 and -11, are more common in the aerodigestive tract; therefore, the majority of the HPV-related aerodigestive tract lesions are benign, such as papilloma of the oral cavity and recurrent respiratory papillomatosis (RRP) of the larynx (20). However, regardless of the low risk, RRP has the potential of spread and progression. Therefore, even 'low-risk' HPVs may progress to cancer.

HPV-16 is the most common high-risk type affecting the aerodigestive tract, and is considered to be associated with a small proportion of oropharyngeal cancers, such as those originating from the tonsils, tonsillar fossa, base of the tongue and soft palate. Of note, the prevalence of HPV-positive oropharyngeal cancers has markedly increased over the past decades (21).

There has always been controversy on the association between HPV infection and esophageal squamous cell carcinoma (ESCC). Numerous studies have attempted to investigate the association between HPV infection and ESCC, but contradictory results were reported. As regards studies detecting HPV DNA in ESCC samples, both negative and positive results have been reported (22-26). However, the mere presence of HPV DNA in ESCC tissues cannot confirm its 
etiological role in tumorigenesis; thus, a large international study (interSCOPE) was designed to determine whether there were anti-L1 or anti-E6/E7 antibodies in the serum of ESCC patients, with only 4 samples found positive for HPV-16 E6 and E7 (27). Further evidence demonstrated no detectable level of HPV DNA integration in ESCC samples $(28,29)$, and the status of HPV infection did not affect the prognosis of ESCC (30). These results indicate that HPV may play a less important role in the development of ESCC, but a hit-and-run mechanism may be utilized by HPV to induce ESCC. Large prospective cohort studies with long follow-up are required to draw definitive conclusions on the involvement of HPVs in esophageal carcinogenesis.

HPV infection of non-genital skin. The HPV types involved in cutaneous infection, including HPV-1, -2, -3, -4, -10, -27, -28 and -41 , among others, are quite different from those involved in mucosal infection, usually causing various types of warts, such as common, flat and plantar warts (31). While cutaneous HPV infection does not ordinarily cause skin cancer, it may become complicated when there is a genetic background of EV. EV patients are susceptible to HPV infection, particularly HPV-5 and -8 , and a certain proportion of EV patients eventually develop skin cancer at the location of primary lesion (32). Therefore, HPV-5 and -8 are considered as possible carcinogens. However, the role of HPVs in non-melanoma skin cancer in the normal population is yet to be fully elucidated.

\section{HPV life cycle}

HPVs are non-enveloped, double-stranded circular DNA viruses with a genome $\sim 8 \mathrm{~kb}$ in size, which consist of three parts: Long control region (LCR), open reading frame (ORF) of six early genes (E1, E2, E4, E5, E6 and E7) and ORF of two late genes (major capsid protein L1 and minor capsid protein L2) (Fig. 1) (33). The viral capsid is an icosahedron composed of 72 pentamers of L1 (360 in total) with variable numbers of L2 buried inside the capsid surface. To date, $>170$ types of HPV have been identified and they may be roughly divided into cutaneotropic and mucotropic types, while certain types of HPV may be found in both cutaneous and mucosal lesions. Those mucosal HPVs are further subdivided into low-risk and high-risk groups, according to their carcinogenic potency. HPVs only infect the basal keratinocytes of human stratified squamous epithelia, such as skin and mucosae. A microwound of the epithelium is a prerequisite for the transmission procedure, which enables HPVs to reach the basement membrane (BM) and basal keratinocytes (34). Additionally, active cell division stimulated by wound healing response is also considered to be necessary for the infection process $(35,36)$. It has been demonstrated that HPVs first bind to heparan sulfate proteoglycans (HSPGs) (37) on the BM through the L1 capsid protein, which induces subsequent conformation of $\mathrm{L} 2$ minor capsid protein to expose its N-terminal, where a furin cleavage site is located (38). Upon furin cleavage, viruses shed from the BM are transferred to the cell surface for secondary binding events mediated by allosteric L1 (39-41), and the RG-1 epitope on L2, which is required for L2-mediated endosomal escape from the late endosomes (42), is exposed. In addition, BM also acts as

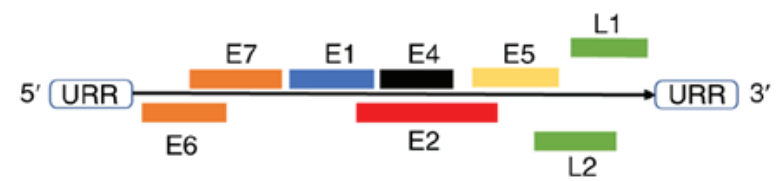

Figure 1. Genome organization of human papillomavirus. URR, upstream regulatory region.

a guidance for HPVs to identify permissive cells, i.e., basal keratinocytes (mitotically active epithelial cells) rather than non-permissive (non-dividing) cells (40). Internalization of the virions follows the secondary binding events, through $\alpha 6 \beta 4$ integrins (43-46), tetraspanins CD63 and CD151 (47-49) and other unidentified receptors.

As regards HPVs adhering to the cell surface through syndecans (HSPGs located on the cell membrane), it is also possible that additional components, such as epidermal growth factor (EGF) and keratinocyte growth factor (KGF), are incorporated after initial binding occurs, forming large-molecular-weight complexes. After cleavage by matrix metalloprotease, these complexes are released from the cell membrane and subsequently bind with EGFR/KGFR, which mediates the uptake of the complexes $(50,51)$.

The endocytosed virions are transported by retrograde trafficking sequentially through the endosomal system, where the capsid disassembles and L1 is retained in a degraded form, while L2 remains associated with viral DNA (vDNA), trans Golgi network, endoplasmic reticulum and, finally, into the nucleus during the nuclear envelope breakdown of mitosis (52).

Following the initial infection by high-risk HPVs, the viral genome tethers the cellular genome as episomes undergo transient amplification to extend to 200 copies per cell, maintaining the viral episome at a low copy number and forming the reservoir of infection (53-55). The life cycle of intracellular viruses is closely associated with the proliferation, differentiation and maturation of keratinocytes, and the expression of viral proteins is likewise highly ordered. In the lower layers of the epithelium, where basal and parabasal cells reside, E6 and E7, referred to as the oncogenic proteins, are expressed to stimulate cell division. E6, targeting p53, mediates its ubiquitination through recruitment of E6AP and proteasome-dependent degradation (56). E7 binds retinoblastoma family proteins and, therefore, releases E2F to activate gene transcription necessary for DNA replication. Thus, coordination of E6 and E7 drives cells to re-enter the cell cycle (35). In addition, E1 helicase is required for viral genome replication, and $\mathrm{E} 2$, which is required for transcription activation and repression, recruits E1 at the beginning of replication. Therefore, E1 may be transiently expressed for the aforementioned initial genome amplification, but not for genome maintenance (57); by contrast, E2 is considered to be constitutively expressed for its role in transcription activation. In the middle layers, with the advent of genome amplification, the necessary proteins E1, E2, E4, E5, E6 and E7 increase in abundance. E6 and E7 are still needed, as they allow cells to re-enter the S-phase, which provides the conditions for viral genome replication (58). E5 plays a role similar to those of E6 and E7, but through stabilization of EGFR and enhancement of EGF signaling and mitogen-activated protein kinase activity (59-61). 

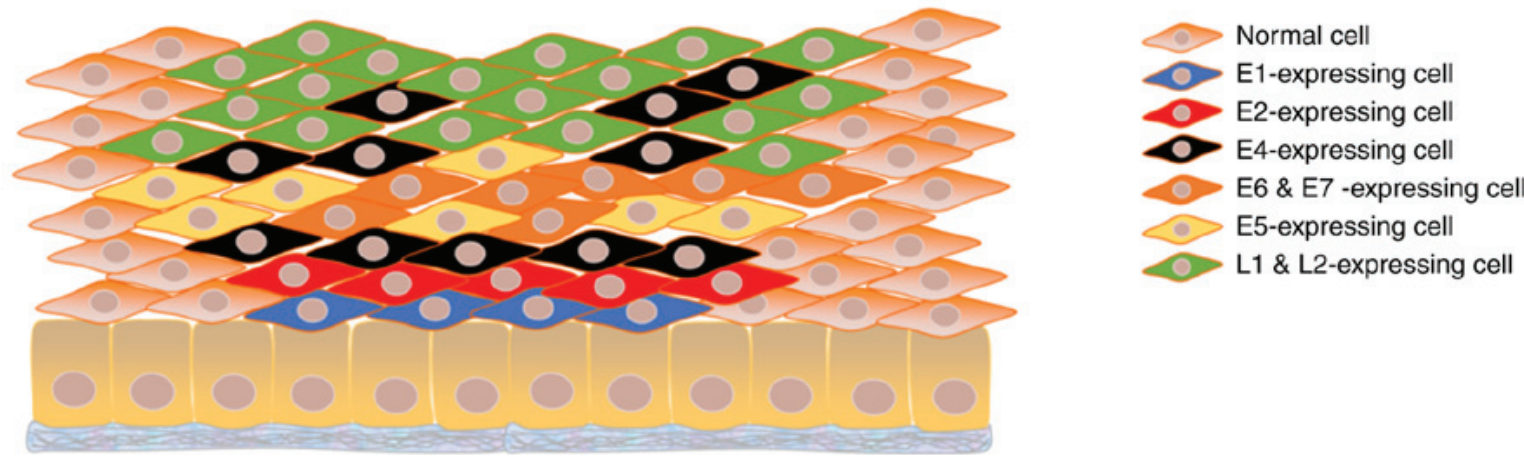

Figure 2. Viral protein expression mode in infected cervical epithelium.

In the upper layers, E4, L1 and L2 are predominantly expressed where packaging of vDNA and assembly of intact virions occur following genome amplification (Fig. 2). The virus is finally released in the superficial layers of stratified epithelium along with the shedding of senescent cells. Apart from virus release, another role of E4 is disintegration of the stratum corneum by formation of amyloid fibers, enabling repetitive infection of HPVs (62-64). On the contrary, this mode is completely changed when lesions progress (to HSIL or ICC), and the definition 'abortive infection' is often used to describe the status where most or all layers of the stratified epithelium are occupied by basal-like cells overexpressing E6 and E7. Viral genome integration is a late event, which deregulates E6 and E7 expression by loss of E2 and is highly associated with invasive lesions (58).

\section{Immune evasion}

HPVs have long been known to employ multiple tactics to escape recognition and elimination by the human immune system, underlying persistent infection.

The unique life cycle of HPV beyond the dermis keeps it away from immunocompetent cells. The factors contributing to the immune invisibility of HPV-infected keratinocytes include the maintenance of low profile of the viral genome in basal cells, non-secretory proteins, low profile of viral proteins via E2 as transcription repressor and suboptimal codon usage $(65,66)$, and the absence of viremia and cell lysis.

HPVs also interfere with normal immune function through the following mechanisms. A dampened type I interferon (IFN) signaling cascade results from inhibition of TYK2 kinase activity (67) and IFN regulatory factor 3 (IRF3) transactivation (68) by E6, as well as inhibition of IRF1 (69) and IRF9 (70) by E7. An impaired antigen-presenting process via the major histocompatibility complex-I (MHC-I), also referred to as human leukocyte antigen (HLA), results from decreased expression of low-molecular-weight polypeptide (LMP)2, LMP7, transporter associated with antigen processing (TAP)1, TAP2 and MHC-I (71). Depletion of Langerhans cells (LC) in the infected epithelium results from downregulation of E-cadherin on the cell membrane of infected keratinocytes $(72,73)$. Blocked maturation of LCs results from activation of the phosphoinositide 3-kinase (PI3K)-Akt pathway in LCs by L2 capsid protein $(74,75)$. A shift from Th1- to Th2-response caused by HPV stimulates interleukin (IL)-10 secretion at the expense of IFN- $\gamma(76,77)$. Furthermore, IL-10 is considered to downregulate the expression of classic HLA-I molecules (76) and upregulate the expression of non-classic HLA-G molecules (78), which suppress the functions of cytotoxic T lymphocytes (CTLs) (79), natural killer (NK) cells (80) and dendritic cells (DCs) (81).

Although the infected cells suffer an immune attack, the apoptosis resistance conferred by E5, which inhibits TRAIL- and CD95L-mediated apoptosis (82-84), as well as E6, which accelerates proteasome degradation of p53, FADD, procaspase-8 and c-Myc (85-87), enable their survival (88).

\section{Chemical antivirals}

Chemical antivirals are crucial for the treatment of several viral infectious diseases, such as viral hepatitis B and acquired immunodeficiency syndrome (AIDS), but little is known on the role of antivirals in HPV infections. This may be partially attributed to the fact that the targets of classical antivirals are enzymes encoded by the viral genome, while HPVs hijack the cellular replication system for their reproduction, except for E1 helicase, which provides few targets for drug design. However, several studies and clinical trials have identified and demonstrated the robust anti-HPV potential of certain acyclic nucleoside phosphonates (ANPs), among which cidofovir is the most extensively investigated.

ANPs. Cidofovir, (S)-1-(3-hydroxy-2-(phosphonomethoxy)propyl) cytosine, was initially designed to inhibit the DNA polymerase and become incorporated into the daughter DNA, slowing down DNA replication and viral genome instability. Further studies have demonstrated its antiviral potential against herpes simplex virus (HSV), which encodes its own DNA polymerase, and against HPV, in which case no HPV-specific DNA polymerase is generated. The underlying mechanisms may involve the fact that cidofovir is more likely to be converted to its active form as triphosphorylated cidofovir in HPV-infected cells compared with uninfected cells (89), or that the single replication origin is the viral episome, in contrast to multiple replication origins in human genome, which is more susceptible to chain-terminating factors, with no substitutive origins or compensatory effects from other origins (90). A phase II clinical trial that adopted topical cidofovir in the treatment of CIN2 and CIN3 reported a $60.8 \%$ response rate in the cidofovir group vs. $20 \%$ in the control group (91). Although conization 
may outperform cidofovir in terms of therapeutic efficacy, these findings have identified an alternative treatment for patients with concerns regarding postoperative complications. Similar studies have been performed on women with high-grade vulval intraepithelial neoplasia, where 4 of 10 had complete regression and 3 had a partial response (92). Another study evaluated the safety and efficacy of topical cidofovir in the treatment of PAIN and VIN in HIV-positive patients, demonstrating $15 \%$ complete response, $36 \%$ partial response, $21 \%$ stable disease and $6 \%$ progressive disease (93).

However, the two hydroxyls in the phosphonic moiety of cidofovir decrease its transmembrane activity, and it may be hypothesized that lipophilic modification of the hydroxyls will enhance its anti-HPV activity. This hypothesis has already been confirmed by adefovir and tenafovir, both resulting in significantly higher efficacy compared with their parent compounds, but exhibiting no specificity for HPV-infected cells (94), whereas GS-9191 exhibited selectivity towards HPV-infected cells with enhanced activity, which was further verified in an animal model (95). More recently, another derivative, octadecyloxyethyl benzyl 9-((2-Phosphonomethoxy) ethyl)guanine (ODE-Bn-PMEG), was designed and demonstrated to be effective in blocking HPV-11, -16 and -18 replication (90). These ANPs appear to be promising, but further studies are required to evaluate their safety and efficacy in vivo.

Antivirals targeting proteins encoded by $H P V$. In contrast to ANPs, antivirals targeting proteins encoded by HPV are characterized by higher specificity. With the exception of E1 helicase inhibitors, the majority of these antivirals are novel chemicals hindering protein-DNA or protein-protein interaction.

As previously mentioned, E1 is recruited to the origin site of HPV genome with the help of E2, followed by assembly into double hexamers to start replication, thus hindering the binding between E1 and E2, or E1/E2 and DNA, which appears to be very promising in lowering viral load. Both hypotheses have been evidenced by indandiones for the former (96-98) and polyamides for the latter (99), respectively. Indandiones were found to be more effective against HPV-6 and -11, rather than high-risk HPV types (97). Further modifications may confer anti-high-risk-HPV activities to these chemicals. In view of the inability of earlier-synthesized polyamides to penetrate the cell membrane, previous studies focused on binding modes between polyamides and DNA, while recent research has resolved this issue through the synthesis of PA1 and PA25, which have been proven effective in reducing viral load in cell experiments $(100,101)$.

The fact that E1 is the only protein encoded by HPV that has enzymatic activity $(102,103)$, together with the indispensability of E1 in genome replication, makes E1 the most promising target for inhibiting viral amplification. Screened out as a small molecule inhibitor of HPV6 E1 (104), biphenysulphonacetic acid affects ATP binding of E1 through allosterism involving Tyr486 (105). Therefore, the activity of biphenysulphonacetic acid appears to be dependent on the amino acid sequence (tyrosine residue) and threedimensional structure of E1, which is somewhat type-specific. Moreover, it lacks activity in cell-based assays due to the high intracellular concentration of ATP (104), which further prevents the currently available compounds from therapeutic application.

The well-known interaction between E6 and E6AP, which mediates the proteasome degradation of $\mathrm{p} 53$, provides another therapeutic target for HPV infection. The recognition of the E6-binding motif on E6AP, defined as an $\alpha$-helix with three leucines on one side and two negatively charged residues on the opposite side, enabled researchers to screen out small molecular inhibitors among therapeutic agents $(106,107)$. Further medicinal development based on this finding may prove to be useful.

Other host proteins utilized by HPV as targets of antiviral therapy. Apart from the cellular replication system, several other host mechanisms usurped by HPV to facilitate its survival and reproduction may serve as targets, and corresponding agents are referred to as host-dependent viral inhibitors.

The oncoprotein E7 was also demonstrated to be associated with class I histone deacetylases (HDAC) 1 and 2 (108) under the mediation of Mi2 $\beta$ (109),responsible for proliferation-promotion and long-term viral episome maintenance (108). HDACs decrease the acetylation state of histones, thereby inhibiting target gene transcription. The relocation of HDACs induced by E7 from proliferation-promoting genes to cell cycle-arresting or apoptosis genes leads to upregulation of the former and downregulation of the latter. Therefore, HDAC inhibitors may be able to interrupt the multiple pathogenic processes. Current HDAC inhibitors are mostly $\mathrm{Zn}^{2+}$-chelating agent binding to the $\mathrm{Zn}$-binding catalytic domain of HDAC, including short-chain fatty acids (110), hydroxamic acids $(111,112)$, benzamide derivatives (113), epoxyketones and cyclic peptides (114). Although these were effective in arresting the proliferation of cervical cancer cells (115-117), they may need further optimization prior to clinical application due to their broad spectrum of cellular targets.

Cyclin-dependent kinase (Cdk) 2, activated by cyclin A or E, is crucial for driving the cell cycle as well as for the pathogenesis of HPV.Cdk2 is stimulated by E7 via multiple mechanisms (118) and subsequently promotes cellular proliferation. $\mathrm{Cdk} 2$ also accelerates viral genome amplification by phosphorylating E1 at specific sites in its N-terminal domain (119-121) and causes abnormal copy numbers of centrosome with genome instability (122-124). Phosphorylation of E1 induces its nuclear retention and, thus, facilitates the formation of hexamers that are necessary for replication initiation $(125,126)$. Inhibitors of $\mathrm{Cdk} 2$, therefore, are considered to halt the proliferation of cervical carcinoma cells and restore normal centrosome replication. Cell-based assays using roscovine $(127,128)$ and indirubin-3'-oxime (IO) (129) have already confirmed this hypothesis. Novel IO derivatives with higher specificity and potency towards Cdk2 have already been discovered (130) and, together with other, more potent $\mathrm{Cdk} 2$ inhibitors, such as flavopiridol, should be further evaluated to establish their role in HPV infection treatment.

The cellular transcription factor Sp1 can also bind to LCR in the viral genome of both low- and high-risk HPV types, and is involved in the transcription of HPV genes (mainly E6 and E7) independently of E2 $(131,132)$. Inhibiting this process with derivatives of nordihydroguaiaretic acid (NDGA), i.e., tetra-O-methyl NDGA and tetra-acetyl NDGA (133), resulted 
in cell growth arrest (134), apoptosis and tumor size reduction in tumor-bearing mice (134).

\section{Therapeutic vaccines}

The etiology of cervical carcinoma as a viral infectious disease established over the last $\sim 50$ years has enabled its prevention through prophylactic vaccination (Fig. 3). Current prophylactic vaccination, however, will not achieve a significant reduction in the morbidity and mortality of cervical carcinoma until successful world coverage by vaccination, which is an elusive goal due to the high cost of HPV vaccines. In addition, it usually takes 10-30 years (median, 23.5 years) for CIN 2/3 to progress to ICC (135); therefore, considering the size of the population with existing HPV infections and the natural history of HPV-associated precancerous diseases, tens of years may pass for the vaccines to exert their protective effects against cervical cancer. In summary, a significant decrease in the incidence of cervical cancer will not be achieved until vaccinated women enter the peak age range of cervical cancer.

The demand for clearance of established HPV infection and regression of precancerous/cancerous lesions has prompted the design of therapeutic vaccines. Apart from the humoral immunity triggered by prophylactic vaccines, therapeutic vaccines trigger cell-mediated immune responses. Among the proteins encoded by HPV, E6 and E7 are the best-characterized and the most extensively investigated due to their carcinogenic role and constitutive expression in infected cells (58). Live vector vaccines or DNA vaccines including wild-type E6 and E7 with the potential to transform cells are usually inactivated at certain sites into detox forms. Other targets include E1, E2 and E5, according to their expression mode during the life cycle of HPV. However, it must be mentioned that once viral genome is integrated, most genes are lost, except E6 and E7, which are expressed at even higher levels without repression of E2 (136-139). Several strategies for the development of therapeutic vaccines have been studied, including live vector, nucleic acid, peptide-based, protein and cellular vaccines, with several vaccine candidates currently in clinical trials (Fig. 4).

As regards the evaluation of immunization efficacy, both antigen-specific $\mathrm{CD}^{+}$and $\mathrm{CD}^{+}$lymphocytes are considered as indicators of cell-mediated immunity. $\mathrm{CD} 8^{+}$lymphocytes further differentiate into CTLs, undertaking the main task of eliminating virus-infected cells, while CD4+ lymphocytes can differentiate into T-helper type 1 (Th1) lymphocytes, playing an auxiliary role in priming antigen-specific CTLs. Other direct outcome evaluation indicators include histopathological regression or complete response rate, histopathological reduction or partial response rate, and viral clearance rate.

Live vector vaccines. Live vector vaccines utilize attenuated bacteria or viruses to transport genes of interest into cells. These microorganisms infect host cells, proliferate intracellularly and spread to surrounding cells in a restricted manner prior to immune elimination. The gene of interest is then expressed by the host protein expression system, leaving the protein at its most natural state. These allow class I MHC antigen presentation by infected cells, but inefficiently. Another more high-efficiency

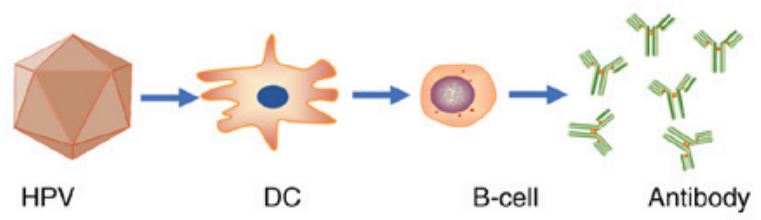

Figure 3. Immunization process of prophylactic vaccines. HPV, human papillomavirus; DC, dendritic cell.

antigen presentation pathway is achieved by dendritic cell (DC) ingestion of free antigen released by infected cells through exosomes, secretion or apoptosis. Thereafter, DCs process antigen and present it on the cell surface for T-cell recognition and activation through both class II and class I (by cross-presentation) MHC pathways. More directly, DCs residing in the vaccination sites (e.g., Langerhans cells in the dermis) may be infected by the live vectors, which simplifies the antigen presentation process. In addition, the vector itself acts as an adjuvant to enhance the immunogenicity of the vaccine due to its pathological nature, thus promoting an even stronger immune response. Unfortunately, live vector vaccines carry the risk of overwhelming infection in immunocompromised patients, and the live vector itself can induce neutralizing antibody production, thus abrogating the boost effect of repeated vaccination. In rare cases, the host may have pre-existing immunity against the live vector, leading to vaccination failure.

Bacterial vector. Bacterial vectors include Listeria monocytogenes $(140,141)$, Lactobacillus casei (142), Lactobacillus lactis (143-145), Lactobacillus plantarum (145) and Salmonella species (146). Lactobacilli are non-invasive and non-commensal bacteria, which are transiently located in mucosae and express recombinant antigen priming mucosal immunity after oral or nasal administration as vaccines. Their favorable safety profile, the low possibility of immune tolerance and the convenient delivery method make Lactobacilli vectors promising candidates, while their immunogenicity remains to be further enhanced, possibly by combining with cytokines or other adjuvant agents. A recombinant Lactobacillus casei vaccine expressing modified HPV-16 E7 has completed its phase I/IIa clinical trial in $17 \mathrm{HPV} 6^{+} \mathrm{CIN} 3$ patients, with 9 patients experiencing disease regression to CIN2, and 5 further regressing to LSIL (147).

Listeria, an intracellular bacterium, is able to infect macrophages and escape from phagosomal degradation with the help of listeriolysin O (LLO) (148); therefore, Listeria vectors can replicate and express recombinant proteins in the cytosol, allowing both class I and class II MHC antigen presentation $(149,150)$. A promising Listeria-based vaccine, Lm-LLO-E7 (also referred to as ADXS11-001) was designed by fusing HPV16 E7 with LLO. A phase I study of 15 patients with metastatic, recurrent, refractory or terminal squamous cell carcinoma of the cervix, demonstrated an increase in the E7-specific $\mathrm{T}$ cells detected among peripheral blood mononuclear cells (PBMCs) of 3 patients and a reduction in tumor size was observed in 4 patients (151). Further clinical trials on HPV-associated cancers are currently ongoing (NCT02399813, NCT02002182, NCT02291055 and NCT01266460). 

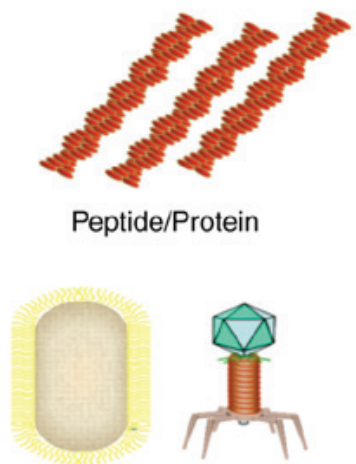

Bacteria/Virus

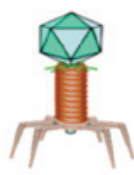

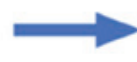

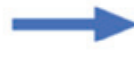

然

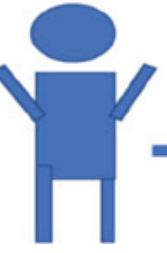

Human

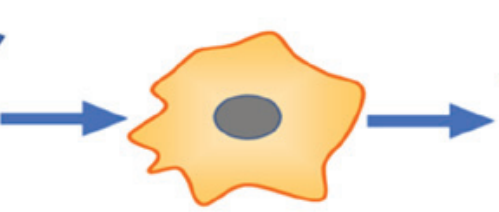

Immature DC
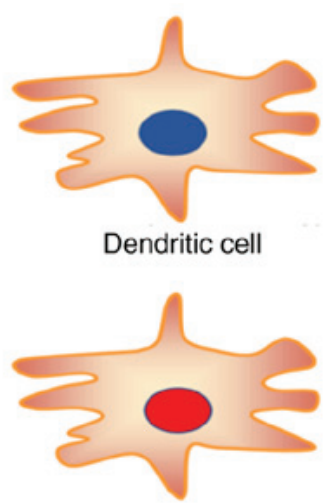

Infected DC

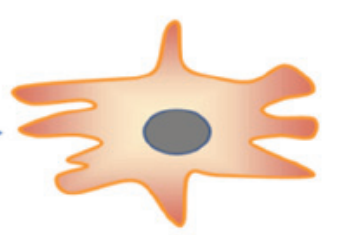

Manipulated DC
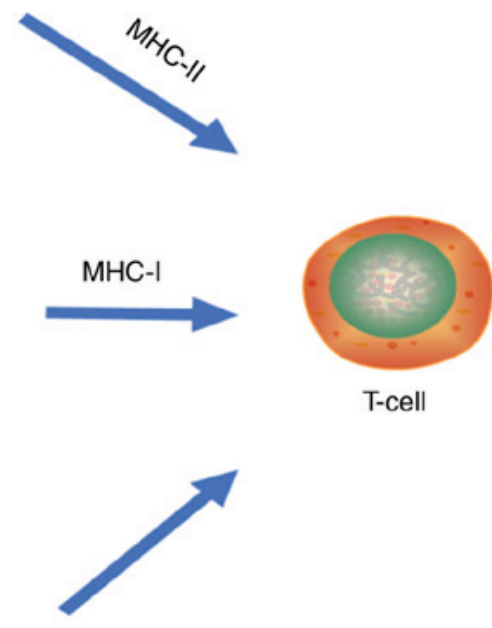

Figure 4. Immunization processes of various therapeutic vaccines. DC, dendritic cell; MHC, major histocompatibility complex.
Viral vector. Viral vectors include adenoviruses, adenoassociated viruses, alphaviruses, lentiviruses and vaccinia viruses. Alphaviruses, including Semliki forest viruses, Sindbis viruses and Venezuelan equine encephalitis viruses are RNA viruses that are transformed into RNA replicon form by substitution of their 3'-terminal structural genes with the genes of interest. These RNA replicons are capable of autonomous amplification but fail to assemble into intact virions due to lack of capsomers. In view of their similarity to nucleic acid vaccines, they will be discussed in the respective section.

TA-HPV is a recombinant vaccinia virus expressing HPV-16/18 E6/E7 with 3 completed clinical trials. A phase I/II study in patients with advanced cervical cancer reported that an HPV-specific CTL response was detected in one of three evaluable patients (152). Another phase I study conducted in patients with International Federation of Gynecology and Obstetrics stage Ib or IIa cervical cancer found that 4 of 29 patients developed an HPV-specific CTL response after a single vaccination (153). A phase II study in patients with HPV-positive high-grade VIN or VAIN with a duration of up to 15 years observed a lesion reduction of at least 50\% in 5 of 12 (42\%) patients, with 1 patient exhibiting complete regression (154).

TG4001 is a recombinant modified vaccinia Ankara (MVA) expressing HPV-16 E6, E7, and IL-2. A phase I study including 21 cases of HPV16 ${ }^{+} \mathrm{CIN} 2 / 3$ patients revealed that $48 \%$ experienced disease regression, whereas $38 \%$ exhibited HPV DNA clearance (155).

MVA E2 is a recombinant MVA expressing BPV E2. In a phase III study in patients with HPV-induced anogenital intraepithelial neoplasia, a 90\% clearance in female patients and $100 \%$ clearance in male patients was reported (156).

Also designed to express the fusion protein of calreticulin and HPV16 E7, adenovirus vector was demonstrated to eradicate established tumors in mice (157). Clinical trials of this vaccine, however, have yet to be conducted.
Subunit vaccines. Antigens delivered in the form of peptides or whole proteins directly are referred to as subunit vaccines. As the most classical type of vaccines, they are considered to be safer compared with live vector vaccines for lack of infectivity and persistent existence.

Peptide vaccines. Peptide vaccines, with an excellent safety profile and good stability, are easy to produce and more cost-effective. However, peptides are truncated from the whole protein and, thus, may not contain the necessary epitopes for DC processing and presentation through the MHC pathway. Furthermore, the fact that each individual has his own HLA type means that epitopes recognized by MHC may differ among different individuals. Therefore, for valid immunization, the epitopes have to be identified so as to match the MHC-specificity of each individual, which limits the mass production of peptide-based vaccines (158). This was addressed by the synthesis of long overlapping peptides covering the entire sequence of the protein. Low immunogenicity is another drawback of peptide-based vaccines, which may be addressed by co-administration of adjuvants, co-expression of cytokines and fusion protein with Toll-like receptor (TLR) ligands.

HPV16-SLP (ISA101) is a peptide-based vaccine consisting of nine HPV16 E6 and four HPV16 E7 synthetic long overlapping peptides with adjuvant Montanide ISA51. In a phase II clinical trial in patients with $\mathrm{HPV} 16^{+}$VIN3, 15 of the 19 patients exhibited a clinical response (79\%), with a complete response in 9 patients (47\%). Moreover, all patients developed a vaccine-induced $\mathrm{T}$-cell response, but patients with stronger IFN- $\gamma$-associated $\mathrm{CD}^{+}$and $\mathrm{CD}^{+}{ }^{+} \mathrm{T}$-cell response were more likely to achieve complete response (159). Other studies have also demonstrated the therapeutic potential of ISA101 (160-163).

PepCan, a vaccine consisting of four HPV16 E6 synthetic peptides and Candin as an adjuvant, has completed the 
dose-escalation phase of a phase I clinical study in patients with HSIL, with $50 \mu \mathrm{g}$ reported as the most effective dose, and histological regression of disease in $45 \%$ of all patients (164).

Protein vaccines. Protein-based vaccines utilize the full-length E6 and/or E7 protein to immunize humans. Compared with peptide-based vaccines, they contain all the epitopes and exclude MHC restriction, but due to their exogenous nature mostly presented by the MHC II pathway (165), they tend to mount humoral immunity and have low immunogenicity. These problems may be overcome by fusion protein targeting them to DCs and giving them access to the MHC I antigen presentation pathway.

TA-CIN is a fusion protein of HPV16 L2, E6 and E7. As the first vaccine that combines therapeutic and prophylactic effects, it was tested on healthy subjects, demonstrating a TA-CIN-specific IgG in 24 of the 32 vaccinated patients and cell-mediated immunity in 25 of the 32 patients (166). A phase II clinical trial conducted in patients with VIN $2 / 3$ combined topical imiquimod and TA-CIN, reporting a $63 \%$ lesion response 1 year after vaccination (167).

GTL001 (Procervix) fused the E7 of HPV-16 and -18 to the catalytically inactive Bordetellla pertussis adenylyl cyclase (CyaA). CyaA is an important toxin of Bordetellla pertussis that binds to integrins on the cell membrane and inserts its $\mathrm{N}$-terminal into the cytoplasm. This characteristic of CyaA is utilized to transport antigens into the cytoplasm, subsequently initiating the MHC I antigen presentation pathway. A phase I trial of GTL001 combined with topical imiquimod in patients positive for HPV-16 or HPV-18 infection, but with normal cytology, showed effectiveness and tolerability (168). Similar strategies have been explored to fuse HPV-16 E7 to a peptide derived from the Limulus polyphemus anti-lipopolysaccharide factor (LALF31-52) in an E. coli expression system (169). LALF31-52 can penetrate cell membranes with immunomodulatory effects increasing its immunogenicity (170). This specially designed vaccine has demonstrated its protective function in a preclinical model (169). Recently, flagellin, ligand of TLR5, was also found to form a fusion protein with HPV16 E7, and its antitumor effects were tested in a mouse model (171).

\section{Nucleic acid vaccines}

DNA vaccines. DNA vaccines are plasmid DNAs carrying genes of interest and transfecting host cells for sustained antigen expression. DNA vaccines usually do not increase neutralizing antibody production, allowing repeated vaccinations (172). However, they raise concerns regarding the risks of exogenous DNA integration, albeit without supportive evidence. Unlike viral vaccines, DNA plasmids cannot autonomously amplify or spread intercellularly, resulting in the main drawback of DNA vaccines, namely poor immunogenicity $(173,174)$.

Intradermal administration via gene gun (175), intramuscular injection with electroporation (176), laser (177), microencapsulation of DNA (178) and fusion protein linking HPV antigens to DC targeting molecules [such as FMS-like tyrosine kinase 3 ligands (179) and heat shock protein (180)] were adopted to increase the antigen-expressing/antigen-loaded DC population. As HPV encodes proteins through suboptimal codons, codon optimization increases antigen expression, further facilitating DC uptake (181-183). Predisposition to MHC class I antigen presentation augments antigen-specific $\mathrm{CD}^{+} \mathrm{T}$-cell response. This can be realized through linkage of HPV antigens to molecules targeting it to endoplasmic reticulum (184) and proteasome (185), including M.tuberculosis hsp70(186), calreticulin(187), heat shock protein Gp96(188), the translocation domain of Pseudomonas aeruginosa exotoxin A (189) and $\gamma$-tubulin (190). MHC I single-chain trimer is another more direct option facilitating antigen presentation on the DC surface (191). Efforts to block T-cell-mediated DC apoptosis $(192,193)$ and DC-mediated T-cell apoptosis (194) were shown to augment $\mathrm{CD} 8^{+} \mathrm{T}$-cell response.

VGX-3100, a DNA vaccine encoding HPV-16/18 E6/E7, which is administered intramuscularly with electroporation, has finished its phase IIb clinical trial in HPV16/18+ CIN2/3 patients. A total of 53/107 (49.5\%) patients with VGX-3100 treatment in contrast to $11 / 36(30.6 \%)$ placebo subjects exhibited histopathological regression in the per-protocol analysis. In addition, 55/114 (48.2\%) patients with VGX-3100 treatment in contrast to $12 / 40(30.0 \%)$ placebo subjects had histopathological regression in the modified intention-to-treat analysis (195).

Other DNA vaccines, such as GX188E (196), pNGVL4a-sig/E7(detox)/HSP70 (197) and pNGVL4a-CRT/ E7(detox) (198), have also demonstrated a good safety profile and effectiveness in several phase I clinical trials.

RNA replicon-based vaccines and suicidal DNA vaccines. RNA replicon-based vaccines are derived from alphaviruses. They replicate intracellularly and express genes of interest with no risk of integration. However, the instability of RNA limits their application and puts forward a more stable form, namely suicidal DNA vaccines, also referred to as DNA-launched RNA replicons. In contrast to RNA replicon-based vaccines, suicidal DNA vaccines have an extra step of transcription into RNA replicons after transfection. Compared with DNA vaccines, the self-replication of these vaccines increases antigen expression, and the final apoptosis of transfected cells resulting from extensive double-stranded RNA production avoids the possibility of genomic integration. However, early apoptosis of host cells causes inadequate stimulation towards $\mathrm{T}$ lymphocytes and insufficient T-cell response. Co-transfection of genes encoding anti-apoptotic proteins in the vector (199) and use of flavivirus Kunjin (KUN) $(200,201)$ have been introduced to address this issue. These vaccines appear to be highly promising for the treatment of HPV infections, but require further investigation.

Cell-based vaccines. Cell-based vaccines include extracting and isolating cells (such as DCs or T lymphocytes) from the peripheral blood or excised tumors of patients, manipulating and expanding them ex vivo, and finally transferring the selected and modified cells back to the patients.

DC-based vaccines. As the most robust antigen-presenting cells (APCs), DCs are mostly studied in the context of immune system activation, circumventing the necessity to access antigens to APCs in vivo and to use adjuvants. Antigen-loaded DCs are produced ex vivo through transfection by viral vectors $(202,203)$, transduction by 
DNA or RNA vectors $(204,205)$, pulsation of antigenic peptides, proteins or tumor cell lysates (205-209). Inevitably, DC-based vaccines have certain drawbacks: First, the production of DC-based vaccines is resource-intensive and individualized, so that large-scale production and widespread use appear to be impractical; second, it is difficult to unify the culturing techniques, which leads to spotty vaccine quality and lack of standard evaluation criteria; third, in order to prime immunity against antigens, DCs have to migrate to lymphoid tissues, and this poses the question of determining the most efficient administration route among intramuscular, subcutaneous, intravenous and intranodal injection, or other options; fourth, the limited longevity of DCs caused by T-cell-mediated apoptosis weakens the magnitude of immune response, which has been partially addressed by transfecting DCs with siRNA silencing pro-apoptotic proteins $(207,208,210)$.

In a phase I clinical study, DCs were pulsed with HPV16/18 E7 and then co-administered with IL-2 back to the patients. An E7-specific $\mathrm{CD}^{+}$response was observed in all patients (211). Another phase I clinical trial was conducted in patients with stage Ib or IIa cervical cancer and DCs were pulsed with HPV16/18 E7 as well as keyhole limpet hemocyanin, promoting DC maturation. As a result, 8 of 10 patients exhibited an increase in E7-specific CD8 ${ }^{+} \mathrm{T}$ lymphocytes (212).

Tumor cell-based vaccines. Isolated tumor cells are engineered to express cytokines such as IL-2 (213,214), IL-12 (215) and granulocyte-macrophage colony-stimulating factor $(214,216)$. Re-administration of tumor cell-based vaccines significantly increases the immunogenicity of tumor cells, thus inducing immune elimination of lesions. Such vaccines do not need to identify certain tumor antigens, and they have been tested in clinical trials in several types of cancer (217). Given that cervical cancer has its own specific antigens, such as E6 and E7, tumor cell-based vaccines may not be the first choice for its treatment. However, tumor cell-based vaccines are associated with the drawback of implanting new cancers in patients, which limits their clinical applicability, particularly in HPV-positive patients with normal cytology or patients with low-grade lesions.

Adoptive cell transfer (ACT). ACT selects tumor antigen-specific CTLs, engineers or activates them and expands them ex vivo, and they are finally re-administered to the patients. A pilot study using HPV16 E6/E7-specific T cells in patients with metastatic cervical cancer reported complete regression in 2 of 9 patients (218). TCR gene-engineered $\mathrm{T}$ cells were also introduced to target $\mathrm{HPV}^{+}$epithelial cancer cells in cell-based assays and exhibited killing avidity (219).

\section{Immunomodulators}

Immunomodulators are agents stimulating innate and/or adaptive immunity for pathogen elimination. As regards treatment of persistent HPV infection, imiquimod is the most extensively studied and widely used immunomodulator.

Imiquimod, an agonist for TLR7, can trigger expression of cytokines and induce a local immune response. The raised levels of cytokines activate local immune cells and initiate immune clearance of HPV-infected cells. Adverse events may include itching, erythema, burning, irritation, tenderness, ulceration and pain. The antiviral as well as antitumor properties of imiquimod have been demonstrated in basal cell carcinoma (220), VAIN (221), VIN (222) and AIN (223). A more popular method is topically applying imiquimod in combination with therapeutic vaccines. However, neither of these treatments have been licensed.

IFN is widely used in the treatment of low-risk HPV-associated anogenital warts, but its role in high-risk HPV-associated pre-cancerous lesions and cancers remains a subject of debate; therefore, more large scale, double-blind, randomized controlled trials are required.

\section{Future prospects}

Candidate therapies for HPV infection mainly include chemical antivirals, therapeutic vaccines and immunomodulators. Therapeutic vaccines appear to be the most promising approach to eliminating HPV in terms of effectiveness, while each type of vaccine comes with its own advantages and disadvantages. Generally, most vaccines must be injected into certain sites, except for Lactobacillus-based vaccines, which are administered orally. Mucosal immunity primed by Lactobacillus-based vaccines satisfies the needs for anti-HPV immunity, as the life cycle of HPV expands beyond the BM. These synergistic factors make Lactobacillus-based vaccines a promising candidate. For all therapeutic vaccines, enhancement of immunogenicity is the common requirement for clinical application.

Antivirals robustly inhibit the proliferation of HPVs, but are unable to eradicate infection, particularly by integrated viruses. The safety profiles of HDAC, Cdk2 and Sp1 inhibitors must be further investigated, as they have numerous downstream targets. It would be preferable to verify the therapeutic effects of these inhibitors at doses not interfering with normal cell functions.

In summary, the coordinated use of various strategies may act synergistically against HPV infection. The combination of prophylactic with therapeutic vaccines, or of different types of therapeutic vaccines as in prime-booster strategy, or of therapeutic vaccines with immunomodulators, antivirals or checkpoint inhibitors, and other similar combinations, may have a profound impact on the treatment of HPV infection.

\section{Acknowledgements}

The authors would like to thank Professor Xia Zhao for her guidance and insightful suggestions.

\section{Funding}

The present study was supported by the Key Research and Development Program of Sichuan Province (grant no. 2017SZ0002) and the State Key Laboratories Development Program of China (grant no. 2018ZX09201018).

\section{Availability of data and materials}

Not applicable. 


\section{Authors' contributions}

YL and HL wrote the initial manuscript. RP created the figures and YY contributed writing material and new ideas. XZ and $\mathrm{XQ}$ revised the manuscript and approved the final version. All authors have read and approved the final version of the manuscript for publication.

\section{Ethics approval and consent to participate}

Not applicable.

\section{Patient consent for publication}

Not applicable.

\section{Competing interests}

The authors declare that they have no competing interests to disclose.

\section{References}

1. Dunne EF, Unger ER, Sternberg M, McQuillan G, Swan DC, Patel SS and Markowitz LE: Prevalence of HPV infection among females in the United States. JAMA 297: 813-819, 2007.

2. Forman D, de Martel C, Lacey CJ, Soerjomataram I, Lortet-Tieulent J, Bruni L, Vignat J, Ferlay J, Bray F, Plummer $\mathrm{M}$ and Franceschi S: Global burden of human papillomavirus and related diseases. Vaccine 30 (Suppl 5): F12-F23, 2012.

3. de Martel C, Plummer M, Vignat J and Franceschi S: Worldwide burden of cancer attributable to HPV by site, country and HPV type. Int J Cancer 141: 664-670, 2017.

4. Plummer M, de Martel C, Vignat J, Ferlay J, Bray F and Franceschi S: Global burden of cancers attributable to infections in 2012: A synthetic analysis. Lancet Glob Health 4: e609-e616, 2016.

5. Ferlay J, Soerjomataram I, Dikshit R, Eser S, Mathers C, Rebelo M, Parkin DM, Forman D and Bray F: Cancer incidence and mortality worldwide: Sources, methods and major patterns in GLOBOCAN 2012. Int J Cancer 136: E359-E386, 2015.

6. Arbyn M, Castellsagué X, de Sanjosé S, Bruni L, Saraiya M, Bray $\mathrm{F}$ and Ferlay J: Worldwide burden of cervical cancer in 2008. Ann Oncol 22: 2675-2686, 2011.

7. Kash N, Lee MA, Kollipara R, Downing C, Guidry J and Tyring SK: Safety and efficacy data on vaccines and immunization to human papillomavirus. J Clin Med 4: 614-633, 2015.

8. Woodman CB, Collins SI and Young LS: The natural history of cervical HPV infection: Unresolved issues. Nat Rev Cancer 7 : 11-22, 2007.

9. Massad LS, Einstein MH, Huh WK, Katki HA, Kinney WK, Schiffman M, Solomon D, Wentzensen N and Lawson HW; 2012 ASCCP Consensus Guidelines Conference: 2012 updated consensus guidelines for the management of abnormal cervical cancer screening tests and cancer precursors. Obstet Gynecol 121: 829-846, 2013.

10. Giuliano AR, Harris R, Sedjo RL, Baldwin S, Roe D, Papenfuss MR, Abrahamsen M, Inserra P, Olvera S and Hatch K: Incidence, prevalence, and clearance of type-specific human papillomavirus infections: The Young Women's Health Study. J Infect Dis 186: 462-469, 2002.

11. Boshart M, Gissmann L, Ikenberg H, Kleinheinz A, Scheurlen W and Zur Hausen H: A new type of papillomavirus DNA, its presence in genital cancer biopsies and in cell lines derived from cervical cancer. EMBO J 3: 1151-1157, 1984

12. Dürst M, Gissmann L, Ikenberg H and Zur Hausen H: A papillomavirus DNA from a cervical carcinoma and its prevalence in cancer biopsy samples from different geographic regions. Proc Natl Acad Sci USA 80: 3812-3815, 1983.

13. Tjalma W: HPV negative cervical cancers and primary HPV screening. Facts Views Vis Obgyn 10: 107-113, 2018.
14. Muñoz N, Bosch FX, de Sanjosé S, Herrero R, Castellsagué X, Shah KV, Snijders PJ and Meijer CJ; International Agency for Research on Cancer Multicenter Cervical Cancer Study Group: Epidemiologic classification of human papillomavirus types associated with cervical cancer. N Engl J Med 348: 518-527, 2003.

15. de Sanjose S, Quint WG, Alemany L, Geraets DT, Klaustermeier JE, Lloveras B, Tous S, Felix A, Bravo LE, Shin HR, et al: Human papillomavirus genotype attribution in invasive cervical cancer: A retrospective cross-sectional worldwide study. Lancet Oncol 11: 1048-1056, 2010.

16. Abramowitz L, Jacquard AC, Jaroud F, Haesebaert J, Siproudhis L, Pradat P, Aynaud O, Leocmach Y, Soubeyrand B, Dachez R, et al: Human papillomavirus genotype distribution in anal cancer in France: The EDiTH V study. Int J Cancer 129: 433-439, 2011.

17. De Vuyst H, Clifford GM, Nascimento MC, Madeleine MM and Franceschi S: Prevalence and type distribution of human papillomavirus in carcinoma and intraepithelial neoplasia of the vulva, vagina and anus: A meta-analysis. Int J Cancer 124: 1626-1636, 2009.

18. Stanley MA, Winder DM, Sterling JC and Goon PK: HPV infection, anal intra-epithelial neoplasia (AIN) and anal cancer: Current issues. BMC Cancer 12: 398, 2012.

19. van Seters M, van Beurden M and de Craen AJ: Is the assumed natural history of vulvar intraepithelial neoplasia III based on enough evidence? A systematic review of 3322 published patients. Gynecol Oncol 97: 645-651, 2005.

20. Gillison ML, Broutian T, Pickard RK, Tong ZY, Xiao W, Kahle L, Graubard BI and Chaturvedi AK: Prevalence of oral HPV infection in the United States, 2009-2010. JAMA 307: 693-703, 2012.

21. Chaturvedi AK, Engels EA, Pfeiffer RM, Hernandez BY, Xiao W, Kim E, Jiang B, Goodman MT, Sibug-Saber M, Cozen W, et al: Human papillomavirus and rising oropharyngeal cancer incidence in the United States. J Clin Oncol 29: 4294-4301, 2011.

22. Koh JS, Lee SS, Baek HJ and Kim YI: No association of high-risk human papillomavirus with esophageal squamous cell carcinomas among Koreans, as determined by polymerase chain reaction. Dis Esophagus 21: 114-117, 2008.

23. Zhang SK, Guo LW, Chen Q, Zhang M, Liu SZ, Quan PL, Lu JB and Sun XB: Prevalence of human papillomavirus 16 in esophageal cancer among the Chinese population: A systematic review and meta-analysis. Asian Pac J Cancer Prev 15: 10143-10149, 2014.

24. Guo F, Liu Y, Wang X, He Z, Weiss NS, Madeleine MM, Liu F, Tian X, Song Y, Pan Y, et al: Human papillomavirus infection and esophageal squamous cell carcinoma: A case-control study. Cancer Epidemiol Biomarkers Prev 21: 780-785, 2012.

25. Yong $\mathrm{F}$, Xudong $\mathrm{N}$ and Lijie T: Human papillomavirus types 16 and 18 in esophagus squamous cell carcinoma: A meta-analysis. Ann Epidemiol 23: 726-734, 2013.

26. Liyanage SS, Rahman B, Ridda I, Newall AT, Tabrizi SN, Garland SM, Segelov E, Seale H, Crowe PJ, Moa A and Macintyre CR: The aetiological role of human papillomavirus in oesophageal squamous cell carcinoma: A meta-analysis. PLoS One 8: e69238, 2013.

27. Sitas F, Egger S, Urban MI, Taylor PR, Abnet CC, Boffetta P, O'Connell DL, Whiteman DC, Brennan P, Malekzadeh R, et al: InterSCOPE study: Associations between esophageal squamous cell carcinoma and human papillomavirus serological markers. J Natl Cancer Inst 104: 147-158, 2012.

28. Cancer Genome Atlas Research Network; Analysis Working Group: Asan University; BC Cancer Agency; Brigham and Women's Hospital; Broad Institute; Brown University; Case Western Reserve University; Dana-Farber Cancer Institute; Duke University, et al: Integrated genomic characterization of oesophageal carcinoma. Nature 541: 169-175, 2017.

29. Liu W, Snell JM, Jeck WR, Hoadley KA, Wilkerson MD, Parker JS, Patel N, Mlombe YB, Mulima G, Liomba NG, et al: Subtyping sub-Saharan esophageal squamous cell carcinoma by comprehensive molecular analysis. JCI Insight 1: e88755, 2016.

30. Guo L, Liu S, Zhang S, Chen Q, Zhang M, Quan P and Sun XB: Human papillomavirus-related esophageal cancer survival: A systematic review and meta-analysis. Medicine (Baltimore) 95: e5318, 2016.

31. Kilkenny M, Merlin K, Young R and Marks R: The prevalence of common skin conditions in Australian school students: 1. Common, plane and plantar viral warts. Br J Dermatol 138: 840-845, 1998 
32. Orth G: Host defenses against human papillomaviruses: Lessons from epidermodysplasia verruciformis. Curr Top Microbiol Immunol 321: 59-83, 2008.

33. Shanmugasundaram S and You J: Targeting persistent human papillomavirus infection. Viruses 9: pii: E229, 2017.

34. Roberts JN, Buck CB, Thompson CD, Kines R, Bernardo M, Choyke PL, Lowy DR and Schiller JT: Genital transmission of HPV in a mouse model is potentiated by nonoxynol-9 and inhibited by carrageenan. Nat Med 13: 857-861, 2007.

35. Doorbar J: Molecular biology of human papillomavirus infection and cervical cancer. Clin Sci (Lond) 110: 525-541, 2006.

36. Schiller JT, Day PM and Kines RC: Current understanding of the mechanism of HPV infection. Gynecol Oncol 118 (1 Suppl): S12-S17, 2010

37. Giroglou T, Florin L, Schäfer F, Streeck RE and Sapp M: Human papillomavirus infection requires cell surface heparan sulfate. J Virol 75: 1565-1570, 2001.

38. Selinka HC, Giroglou T, Nowak T, Christensen ND and Sapp M: Further evidence that papillomavirus capsids exist in two distinct conformations. J Virol 77: 12961-12967, 2003.

39. Day PM, Gambhira R, Roden RB, Lowy DR and Schiller JT: Mechanisms of human papillomavirus type 16 neutralization by 12 cross-neutralizing and 11 type-specific antibodies. J Virol 82: 4638-4646, 2008

40. Kines RC, Thompson CD, Lowy DR, Schiller JT and Day PM: The initial steps leading to papillomavirus infection occur on the basement membrane prior to cell surface binding. Proc Natl Acad Sci USA 106: 20458-20463, 2009.

41. Richards KF, Bienkowska-Haba M, Dasgupta J, Chen XS and Sapp M: Multiple heparan sulfate binding site engagements are required for the infectious entry of human papillomavirus type 16. J Virol 87: 11426-11437, 2013.

42. Richards RM, Lowy DR, Schiller JT and Day PM: Cleavage of the papillomavirus minor capsid protein, L2, at a furin consensus site is necessary for infection. Proc Natl Acad Sci USA 103 $1522-1527,2006$.

43. Evander M, Frazer IH, Payne E, Qi YM, Hengst K and McMillan NA: Identification of the alpha6 integrin as a candidate receptor for papillomaviruses. J Virol 71: 2449-2456, 1997.

44. Abban CY and Meneses PI: Usage of heparan sulfate, integrins, and FAK in HPV16 infection. Virology 403: 1-16, 2010.

45. Huang HS and Lambert PF: Use of an in vivo animal model for assessing the role of integrin a(6) $\beta(4)$ and syndecan- 1 in early steps in papillomavirus infection. Virology 433: 395-400, 2012 .

46. Aksoy P, Abban CY, Kiyashka E, Qiang W and Meneses PI: HPV16 infection of HaCaTs is dependent on $\beta 4$ integrin, and a6 integrin processing. Virology 449: 45-52, 2014.

47. Scheffer KD, Berditchevski F and Florin L: The tetraspanin CD151 in papillomavirus infection. Viruses 6: 893-908, 2014.

48. Spoden, G, Freitag K, Husmann M, Boller K, Sapp M, Lambert C and Florin L: Clathrin- and caveolin-independent entry of human papillomavirus type 16-involvement of tetraspanin-enriched microdomains (TEMs). PLoS One 3: e3313, 2008.

49. Scheffer, KD, Gawlitza A, Spoden GA, Zhang XA, Lambert C, Berditchevski $\mathrm{F}$ and Florin L: Tetraspanin CD151 mediates papillomavirus type 16 endocytosis. J Virol 87: 3435-3446, 2013.

50. Surviladze Z, Dziduszko A and Ozbun MA: Essential roles for soluble virion-associated heparan sulfonated proteoglycans and growth factors in human papillomavirus infections. PLoS Pathog 8: e1002519, 2012.

51. Cerqueira C, Samperio Ventayol P, Vogeley C and Schelhaas M: Kallikrein-8 proteolytically processes human papillomaviruses in the extracellular space to facilitate entry into host cells J Virol 89: 7038-7052, 2015.

52. Aksoy P, Gottschalk EY and Meneses PI: HPV entry into cells Mutat Res Rev Mutat Res 772: 13-22, 2017.

53. Pyeon D, Pearce SM, Lank SM, Ahlquist P and Lambert PF Establishment of human papillomavirus infection requires cell cycle progression. PLoS Pathog 5: e1000318, 2009.

54. Parish JL, Bean AM, Park RB and Androphy EJ: ChlR1 is required for loading papillomavirus E2 onto mitotic chromosomes and viral genome maintenance. Mol Cell 24: 867-876, 2006.

55. McBride AA: Replication and partitioning of papillomavirus genomes. Adv Virus Res 72: 155-205, 2008.

56. Tomaić V, Pim D and Banks L: The stability of the human papillomavirus E6 oncoprotein is E6AP dependent. Virology 393: $7-10,2009$
57. Egawa N, Nakahara T, Ohno S, Narisawa-Saito M, Yugawa T, Fujita M, Yamato K, Natori Y and Kiyono T: The E1 protein of human papillomavirus type 16 is dispensable for maintenance replication of the viral genome. J Virol 86: 3276-3283, 2012.

58. Doorbar J, Quint W, Banks L, Bravo IG, Stoler M, Broker TR and Stanley MA: The biology and life-cycle of human papillomaviruses. Vaccine 30 (Suppl 5): F55-F70, 2012.

59. Genther SM, Sterling S, Duensing S, Münger K, Sattler C and Lambert PF: Quantitative role of the human papillomavirus type 16 E5 gene during the productive stage of the viral life cycle. J Virol 77: 2832-2842, 2003.

60. Fehrmann F, Klumpp DJ and Laimins LA: Human papillomavirus type 31 E5 protein supports cell cycle progression and activates late viral functions upon epithelial differentiation. J Virol 77: 2819-2831, 2003.

61. Pim D, Collins M and Banks L: Human papillomavirus type 16 E5 gene stimulates the transforming activity of the epidermal growth factor receptor. Oncogene 7: 27-32, 1992.

62. Wang Q, Griffin H, Southern S, Jackson D, Martin A, McIntosh P, Davy C, Masterson PJ, Walker PA, Laskey P, et al: Functional analysis of the human papillomavirus type $16 \mathrm{E} 1=\mathrm{E} 4$ protein provides a mechanism for in vivo and in vitro keratin filament reorganization. J Virol 78: 821-833, 2004.

63. McIntosh PB, Martin SR, Jackson DJ, Khan J, Isaacson ER, Calder L, Raj K, Griffin HM, Wang Q, Laskey P, et al: Structural analysis reveals an amyloid form of the human papillomavirus type 16 E1-E4 protein and provides a molecular basis for its accumulation. J Virol 82: 8196-8203, 2008.

64. Brown DR, Kitchin D, Qadadri B, Neptune N, Batteiger T and Ermel A: The human papillomavirus type $11 \mathrm{E} 1-\mathrm{E} 4$ protein is a transglutaminase 3 substrate and induces abnormalities of the cornified cell envelope. Virology 345: 290-298, 2006.

65. Zhao KN and Chen J: Codon usage roles in human papillomavirus. Rev Med Virol 21: 397-411, 2011.

66. Zhou J, Liu WJ, Peng SW, Sun XY and Frazer I: Papillomavirus capsid protein expression level depends on the match between codon usage and tRNA availability. J Virol 73: 4972-4982, 1999.

67. Li S, Labrecque S, Gauzzi MC, Cuddihy AR, Wong AH, Pellegrini S, Matlashewski GJ and Koromilas AE: The human papilloma virus (HPV)-18 E6 oncoprotein physically associates with Tyk2 and impairs Jak-STAT activation by interferon-alpha. Oncogene 18: 5727-5737, 1999.

68. Ronco LV, Karpova AY, Vidal M and Howley PM: Human papillomavirus $16 \mathrm{E} 6$ oncoprotein binds to interferon regulatory factor-3 and inhibits its transcriptional activity. Genes Dev 12: 2061-2072, 1998 .

69. Um SJ, Rhyu JW, Kim EJ, Jeon KC, Hwang ES and Park JS: Abrogation of IRF-1 response by high-risk HPV E7 protein in vivo. Cancer Lett 179: 205-212, 2002.

70. Barnard PE Payne E and McMillan NA: The human papillomavirus E7 protein is able to inhibit the antiviral and anti-growth functions of interferon-alpha. Virology 277: 411-419, 2000.

71. Evans M, Borysiewicz LK, Evans AS, Rowe M, Jones M, Gileadi U, Cerundolo V and Man S: Antigen processing defects in cervical carcinomas limit the presentation of a CTL epitope from human papillomavirus 16 E6. J Immunol 167: 5420-5428, 2001.

72. Matthews K, Leong CM, Baxter L, Inglis E, Yun K, Bäckström BT, Doorbar J and Hibma M: Depletion of Langerhans cells in human papillomavirus type 16-infected skin is associated with E6-mediated down regulation of E-cadherin. J Virol 77: 8378-8385, 2003.

73. D'Costa ZJ, Leong CM, Shields J, Matthews C and Hibma MH: Screening of drugs to counteract human papillomavirus 16 E6 repression of E-cadherin expression. Invest New Drugs 30: 2236-2251, 2012

74. Fausch SC, Fahey LM, Da Silva DM and Kast WM: Human papillomavirus can escape immune recognition through Langerhans cell phosphoinositide 3-kinase activation. J Immunol 174: 7172-7178, 2005

75. Fahey LM, Raff AB, Da Silva DM and Kast WM: A major role for the minor capsid protein of human papillomavirus type 16 in immune escape. J Immunol 183: 6151-6156, 2009.

76. Mota F, Rayment N, Chong S, Singer A and Chain B: The antigen-presenting environment in normal and human papillomavirus (HPV)-related premalignant cervical epithelium. Clin Exp Immunol 116: 33-40, 1999.

77. de Jong A, van Poelgeest MI, van der Hulst JM, Drijfhout JW, Fleuren GJ, Melief CJ, Kenter G, Offringa R and van der Burg SH: Human papillomavirus type 16-positive cervical cancer is associated with impaired CD4+ T-cell immunity against early antigens E2 and E6. Cancer Res 64: 5449-5455, 2004 
78. Rodriguez JA, Galeano L, Palacios DM, Gómez C, Serrano ML, Bravo MM and Combita AL: Altered HLA class I and HLA-G expression is associated with IL-10 expression in patients with cervical cancer. Pathobiology 79: 72-83, 2012

79. Le Gal FA, Riteau B, Sedlik C, Khalil-Daher I, Menier C, Dausset J, Guillet JG, Carosella ED and Rouas-Freiss N: HLA-G-mediated inhibition of antigen-specific cytotoxic T lymphocytes. Int Immunol 11: 1351-1356, 1999.

80. Marchal-Bras-Goncalves R, Rouas-Freiss N, Connan F, Choppin J, Dausset J, Carosella ED, Kirszenbaum M and Guillet J: A soluble HLA-G protein that inhibits natural killer cell-mediated cytotoxicity. Transplant Proc 33: 2355-2359, 2001

81. Gros F, Cabillic F, Toutirais O, Maux AL, Sebti Y and Amiot L Soluble HLA-G molecules impair natural killer/dendritic cell crosstalk via inhibition of dendritic cells. Eur J Immunol 38 742-749, 2008.

82. Kabsch K, Mossadegh N, Kohl A, Komposch G, Schenkel J, Alonso A and Tomakidi P: The HPV-16 E5 protein inhibits TRAIL- and FasL-mediated apoptosis in human keratinocyte raft cultures. Intervirology 47: 48-56, 2004.

83. Venuti A, Paolini F, Nasir L, Corteggio A, Roperto S, Campo MS and Borzacchiello G: Papillomavirus E5: The smallest oncoprotein with many functions. Mol Cancer 10: 140, 2011.

84.Lagunas-Martínez A, Madrid-Marina V and Gariglio P: Modulation of apoptosis by early human papillomavirus proteins in cervical cancer. Biochim Biophys Acta 1805: 6-16, 2010.

85. Gross-Mesilaty S, Reinstein E, Bercovich B, Tobias KE, Schwartz AL, Kahana C and Ciechanover A: Basal and human papillomavirus E6 oncoprotein-induced degradation of Myc proteins by the ubiquitin pathway. Proc Natl Acad Sci USA 95 8058-8063, 1998.

86. Filippova M, Parkhurst L and Duerksen-Hughes PJ: The human papillomavirus 16 E6 protein binds to Fas-associated death domain and protects cells from Fas-triggered apoptosis. J Biol Chem 279: 25729-25744, 2004.

87. Garnett TO, Filippova M and Duerksen-Hughes PJ: Accelerated degradation of FADD and procaspase 8 in cells expressing human papilloma virus 16 E6 impairs TRAIL-mediated apoptosis. Cell Death Differ 13: 1915-1926, 2006.

88. Garnett TO and Duerksen-Hughes PJ: Modulation of apoptosis by human papillomavirus (HPV) oncoproteins. Arch Virol 151: 2321-2335, 2006.

89. Johnson JA and Gangemi JD: Selective inhibition of human papillomavirus-induced cell proliferation by (S)-1-[3-hydroxy2-(phosphonylmethoxy)propyl]cytosine. Antimicrob Agents Chemother 43: 1198-1205, 1999.

90. Beadle JR, Valiaeva N, Yang G, Yu JH, Broker TR, Aldern KA, Harden EA, Keith KA, Prichard MN, Hartman T, et al: Synthesis and antiviral evaluation of octadecyloxyethyl Benzyl 9-[(2-Phosphonomethoxy)ethyl]guanine (ODE-Bn-PMEG), a potent inhibitor of transient HPV DNA amplification. J Med Chem 59: 10470-10478, 2016.

91. Van Pachterbeke C, Bucella D, Rozenberg S, Manigart Y, Gilles C, Larsimont D, Vanden Houte K, Reynders M, Snoeck R, Bossens M, et al: Topical treatment of CIN 2+ by cidofovir: Results of a phase II, double-blind, prospective, placebo-controlled study. Gynecol Oncol 115: 69-74, 2009.

92. Tristram A and Fiander A: Clinical responses to Cidofovir applied topically to women with high grade vulval intraepithelial neoplasia. Gynecol Oncol 99: 652-655, 2005.

93. Stier EA, Goldstone SE, Einstein MH, Jay N, Berry JM, Wilkin T, Lee JY, Darragh TM, Da Costa M, Panther L, et al Safety and efficacy of topical cidofovir to treat high-grade perianal and vulvar intraepithelial neoplasia in HIV-positive men and women. AIDS 27: 545-551, 2013

94. Pertusati F, Hinsinger K, Flynn ÁS, Powell N, Tristram A, Balzarini J and McGuigan C: PMPA and PMEA prodrugs for the treatment of HIV infections and human papillomavirus (HPV) associated neoplasia and cancer. Eur J Med Chem 78: 259-268, 2014.

95. Wolfgang GH, Shibata R, Wang J, Ray AS, Wu S, Doerrfler E, Reiser H, Lee WA, Birkus G, Christensen ND, et al: GS-9191 is a novel topical prodrug of the nucleotide analog 9-(2-phosphonylmethoxyethyl)guanine with antiproliferative activity and possible utility in the treatment of human papillomavirus lesions. Antimicrob Agents Chemother 53: 2777-2784, 2009.

96. Yoakim C, Ogilvie WW, Goudreau N, Naud J, Haché B, O'Meara JA, Cordingley MG, Archambault J and White PW: Discovery of the first series of inhibitors of human papillomavirus type 11: Inhibition of the assembly of the E1-E2-Origin DNA complex. Bioorg Med Chem Lett 13: 2539-2541, 2003.
97. White PW, Titolo S, Brault K, Thauvette L, Pelletier A, Welchner E, Bourgon L, Doyon L, Ogilvie WW, Yoakim C, et al: Inhibition of human papillomavirus DNA replication by small molecule antagonists of the E1-E2 protein interaction. J Biol Chem 278: 26765-26772, 2003.

98. Wang Y, Coulombe R, Cameron DR, Thauvette L, Massariol MJ, Amon LM, Fink D, Titolo S, Welchner E, Yoakim C, et al: Crystal structure of the E2 transactivation domain of human papillomavirus type 11 bound to a protein interaction inhibitor. J Biol Chem 279: 6976-6985, 2004.

99. Schaal TD, Mallet WG, McMinn DL, Nguyen NV, Sopko MM, John S and Parekh BS: Inhibition of human papilloma virus E2 DNA binding protein by covalently linked polyamides. Nucleic Acids Res 31: 1282-1291, 2003.

100. Edwards TG, Koeller KJ, Slomczynska U, Fok K, Helmus M, Bashkin JK and Fisher C: HPV episome levels are potently decreased by pyrrole-imidazole polyamides. Antiviral Res 91: 177-186, 2011.

101. Vasilieva E, Niederschulte J, Song Y, Harris GD Jr, Koeller KJ, Liao P, Bashkin JK and Dupureur CM: Interactions of two large antiviral polyamides with the long control region of HPV16. Biochimie 127: 103-114, 2016.

102. Wilson VG, West M, Woytek K and Rangasamy D: Papillomavirus E1 proteins: Form, function, and features. Virus Genes 24: 275-290, 2002.

103. Stenlund A: Initiation of DNA replication: Lessons from viral initiator proteins. Nat Rev Mol Cell Biol 4: 777-785, 2003.

104. Faucher AM, White PW, Brochu C, Grand-Maître C, Rancourt J and Fazal G: Discovery of small-molecule inhibitors of the ATPase activity of human papillomavirus E1 helicase. J Med Chem 47: 18-21, 2004.

105. White PW, Faucher AM, Massariol MJ, Welchner E, Rancourt J, Cartier M and Archambault J: Biphenylsulfonacetic acid inhibitors of the human papillomavirus type $6 \mathrm{E} 1$ helicase inhibit ATP hydrolysis by an allosteric mechanism involving tyrosine 486 . Antimicrob Agents Chemother 49: 4834-4842, 2005.

106. Be X, Hong Y, Wei J, Androphy EJ, Chen JJ and Baleja JD: Solution structure determination and mutational analysis of the papillomavirus E6 interacting peptide of E6AP. Biochemistry 40: 1293-1299, 2001.

107. Baleja JD, Cherry JJ, Liu Z, Gao H, Nicklaus MC, Voigt JH, Chen JJ and Androphy EJ: Identification of inhibitors to papillomavirus type 16 E6 protein based on three-dimensional structures of interacting proteins. Antiviral Res 72: 49-59, 2006.

108. Longworth MS and Laimins LA: The binding of histone deacetylases and the integrity of zinc finger-like motifs of the E7 protein are essential for the life cycle of human papillomavirus type 31. J Virol 78: 3533-3541, 2004.

109. Brehm A, Nielsen SJ, Miska EA, McCance DJ, Reid JL, Bannister AJ and Kouzarides T: The E7 oncoprotein associates with $\mathrm{Mi} 2$ and histone deacetylase activity to promote cell growth. Embo J 18: 2449-2458, 1999.

110. Lu Q, Yang YT, Chen CS, Davis M, Byrd JC, Etherton MR, Umar A and Chen CS: Zn2+-chelating motif-tethered short-chain fatty acids as a novel class of histone deacetylase inhibitors. J Med Chem 47: 467-474, 2004.

111. Suzuki T, Matsuura A, Kouketsu A, Nakagawa H and Miyata N: Identification of a potent non-hydroxamate histone deacetylase inhibitor by mechanism-based drug design. Bioorg Med Chem Lett 15: 331-335, 2005

112. Suzuki T, Nagano Y, Kouketsu A, Matsuura A, Maruyama S, Kurotaki M, Nakagawa $\mathrm{H}$ and Miyata N: Novel inhibitors of human histone deacetylases: Design, synthesis, enzyme inhibition, and cancer cell growth inhibition of SAHA-based non-hydroxamates. J Med Chem 48: 1019-1032, 2005.

113. Suzuki T, Ando T, Tsuchiya K, Fukazawa N, Saito A, Mariko Y, Yamashita T and Nakanishi O: Synthesis and histone deacetylase inhibitory activity of new benzamide derivatives. J Med Chem 42: 3001-3003, 1999.

114. Nakajima H, Kim YB, Terano H, Yoshida M and Horinouchi S FR901228, a potent antitumor antibiotic, is a novel histone deacetylase inhibitor. Exp Cell Res 241: 126-133, 1998.

115. Finzer P, Ventz R, Kuntzen C, Seibert N, Soto U and Rösl F: Growth arrest of HPV-positive cells after histone deacetylase inhibition is independent of E6/E7 oncogene expression. Virology 304: 265-273, 2002.

116. Finzer P, Kuntzen C, Soto U, zur Hausen H and Rösl F: Inhibitors of histone deacetylase arrest cell cycle and induce apoptosis in cervical carcinoma cells circumventing human papillomavirus oncogene expression. Oncogene 20: 4768-4776, 2001. 
117. Chavez-Blanco A, Perez-Plasencia C, Perez-Cardenas E, Carrasco-Legleu C, Rangel-Lopez E, Segura-Pacheco B, Taja-Chayeb L, Trejo-Becerril C, Gonzalez-Fierro A, Candelaria M, et al: Antineoplastic effects of the DNA methylation inhibitor hydralazine and the histone deacetylase inhibitor valproic acid in cancer cell lines. Cancer Cell Int 6: 2, 2006

118. Hebner CM and Laimins LA: Human papillomaviruses: Basic mechanisms of pathogenesis and oncogenicity. Rev Med Virol 16: 83-97, 2006.

119. Lin BY, Ma T, Liu JS, Kuo SR, Jin G, Broker TR, Harper JW and Chow LT: HeLa cells are phenotypically limiting in cyclin E/CDK2 for efficient human papillomavirus DNA replication. J Biol Chem 275: 6167-6174, 2000.

120. Ma T, Zou N, Lin BY, Chow LT and Harper JW: Interaction between cyclin-dependent kinases and human papillomavirus replication-initiation protein E1 is required for efficient viral replication. Proc Natl Acad Sci USA 96: 382-387, 1999.

121. Cueille N, Nougarede R, Mechali F, Philippe M and Bonne-Andrea C: Functional interaction between the bovine papillomavirus virus type 1 replicative helicase E1 and cyclin E-Cdk2. J Virol 72: 7255-7262, 1998.

122. Duensing S and Münger K: Human papillomaviruses and centrosome duplication errors: Modeling the origins of genomic instability. Oncogene 21: 6241-6248, 2002.

123. Duensing S and Münger K: Centrosome abnormalities and genomic instability induced by human papillomavirus oncoproteins. Prog Cell Cycle Res 5: 383-391, 2003.

124.Duensing S, Duensing A, Flores ER, Do A, Lambert PF and Münger K: Centrosome abnormalities and genomic instability by episomal expression of human papillomavirus type 16 in raft cultures of human keratinocytes. J Virol 75: 7712-7716, 2001.

125. Hsu CY, Mechali F and Bonne-Andrea C: Nucleocytoplasmic shuttling of bovine papillomavirus E1 helicase downregulates viral DNA replication in S phase. J Virol 81: 384-394, 2007.

126. Deng W, Lin BY, Jin G, Wheeler CG, Ma T, Harper JW, Broker TR and Chow LT: Cyclin/CDK regulates the nucleocytoplasmic localization of the human papillomavirus E1 DNA helicase. J Virol 78: 13954-13965, 2004.

127. Schang LM: Cyclin-dependent kinases as cellular targets for antiviral drugs. J Antimicrob Chemother 50: 779-792, 2002

128. Vitali L, Yakisich JS, Vita MF, Fernandez A, Settembrini L, Siden A, Cruz M, Carminatti H, Casas O and Idoyaga Vargas V: Roscovitine inhibits ongoing DNA synthesis in human cervical cancer. Cancer Lett 180: 7-12, 2002.

129. Duensing S, Duensing A, Lee DC, Edwards KM, Piboonniyom SO, Manuel E, Skaltsounis L, Meijer L and Münger K: Cyclin-dependent kinase inhibitor indirubin-3'-oxime selectively inhibits human papillomavirus type 16 E7-induced numerical centrosome anomalies. Oncogene 23: 8206-8215, 2004

130. Yan L, Lai F, Chen X and Xiao Z: Discovery of novel indirubin-3'-monoxime derivatives as potent inhibitors against CDK2 and CDK9. Bioorg Med Chem Lett 25: 2447-2451, 2015.

131. Gloss B and Bernard HU: The E6/E7 promoter of human papillomavirus type 16 is activated in the absence of $\mathrm{E} 2$ proteins by a sequence-aberrant Spl distal element. J Virol 64: 5577-5584, 1990.

132. Butz K and Hoppe-Seyler F: Transcriptional control of human papillomavirus (HPV) oncogene expression: Composition of the HPV type 18 upstream regulatory region. J Virol 67: 6476-6486, 1993.

133. Craigo J, Callahan M, Huang RC and DeLucia AL: Inhibition of human papillomavirus type 16 gene expression by nordihydroguaiaretic acid plant lignan derivatives. Antiviral Res 47: $19-28,2000$

134. Heller JD, Kuo J, Wu TC, Kast WM and Huang RC: Tetra-O-methyl nordihydroguaiaretic acid induces G2 arrest in mammalian cells and exhibits tumoricidal activity in vivo. Cancer Res 61: 5499-5504. 2001.

135. Vink MA, Bogaards JA, van Kemenade FJ, de Melker HE, Meijer CJ and Berkhof J: Clinical progression of high-grade cervical intraepithelial neoplasia: Estimating the time to preclinical cervical cancer from doubly censored national registry data. Am J Epidemiol 178: 1161-1169, 2013.

136. Schwarz E, Freese UK, Gissmann L, Mayer W, Roggenbuck B, Stremlau A and Zur Hausen H: Structure and transcription of human papillomavirus sequences in cervical carcinoma cells. Nature 314: 111-114, 1985.
137. Yu T, Ferber MJ, Cheung TH, Chung TK, Wong YF and Smith DI: The role of viral integration in the development of cervical cancer. Cancer Genet Cytogenet 158: 27-34, 2005.

138. Jeon S, Allen-Hoffmann BL and Lambert PF: Integration of human papillomavirus type 16 into the human genome correlates with a selective growth advantage of cells. J Virol 69: 2989-2997, 1995.

139. Jeon S and Lambert PF: Integration of human papillomavirus type 16 DNA into the human genome leads to increased stability of E6 and E7 mRNAs: Implications for cervical carcinogenesis. Proc Natl Acad Sci USA 92: 1654-1658, 1995.

140. Souders NC, Sewell DA, Pan ZK, Hussain SF, Rodriguez A, Wallecha A and Paterson Y: Listeria-based vaccines can overcome tolerance by expanding low avidity CD8+ T cells capable of eradicating a solid tumor in a transgenic mouse model of cancer. Cancer Immun 7: 2, 2007.

141. Sewell DA, Pan ZK and Paterson Y: Listeria-based HPV-16 E7 vaccines limit autochthonous tumor growth in a transgenic mouse model for HPV-16 transformed tumors. Vaccine 26: 5315-5320, 2008.

142. Adachi K, Kawana K, Yokoyama T, Fujii T, Tomio A, Miura S, Tomio K, Kojima S, Oda K, Sewaki T, et al: Oral immunization with a Lactobacillus casei vaccine expressing human papillomavirus (HPV) type 16 E7 is an effective strategy to induce mucosal cytotoxic lymphocytes against HPV16 E7. Vaccine 28: 2810-2817, 2010.

143. Bermudez-Humaran LG, Langella P, Miyoshi A, Gruss A, Guerra RT, Montes de Oca-Luna R and Le Loir Y: Production of human papillomavirus type $16 \mathrm{E} 7$ protein in Lactococcus lactis. Appl Environ Microbiol 68: 917-922, 2002.

144. Bermudez-Humaran LG, Cortes-Perez NG, Le Loir Y, Alcocer-González JM, Tamez-Guerra RS, de Oca-Luna RM and Langella P: An inducible surface presentation system improves cellular immunity against human papillomavirus type 16 E7 antigen in mice after nasal administration with recombinant lactococci. J Med Microbiol 53: 427-433, 2004.

145. Cortes-Perez NG, Azevedo V, Alcocer-González JM, Rodriguez-Padilla C, Tamez-Guerra RS, Corthier G, Gruss A, Langella P and Bermúdez-Humarán LG: Cell-surface display of E7 antigen from human papillomavirus type-16 in Lactococcus lactis and in Lactobacillus plantarum using a new cell-wall anchor from lactobacilli. J Drug Target 13: 89-98, 2005.

146. Krul MR, Tijhaar EJ, Kleijne JA, Van Loon AM, Nievers MG, Schipper H, Geerse L, Van der Kolk M, Steerenberg PA, Mooi FR and Den Otter W: Induction of an antibody response in mice against human papillomavirus (HPV) type 16 after immunization with HPV recombinant Salmonella strains. Cancer Immunol Immunother 43: 44-48, 1996.

147. Kawana K, Adachi K, Kojima S, Taguchi A, Tomio K, Yamashita A, Nishida $H$, Nagasaka K, Arimoto $T$, Yokoyama T, et al: Oral vaccination against HPV E7 for treatment of cervical intraepithelial neoplasia grade 3 (CIN3) elicits E7-specific mucosal immunity in the cervix of CIN3 patients. Vaccine 32: 6233-6239, 2014.

148. Schnupf P and Portnoy DA: Listeriolysin O: A phagosome-specific lysin. Microbes Infect 9: 1176-1187, 2007.

149. Chen Z, Ozbun L, Chong N, Wallecha A, Berzofsky JA and Khleif SN: Episomal expression of truncated listeriolysin $\mathrm{O}$ in LmddA-LLO-E7 vaccine enhances antitumor efficacy by preferentially inducing expansions of CD4+FoxP3- and CD8+ T cells. Cancer Immunol Res 2: 911-922, 2014.

150. Peters $C$ and Paterson Y: Enhancing the immunogenicity of bioengineered Listeria monocytogenes by passaging through live animal hosts. Vaccine 21: 1187-1194, 2003.

151. Maciag PC, Radulovic S and Rothman J: The first clinical use of a live-attenuated Listeria monocytogenes vaccine: A Phase I safety study of Lm-LLO-E7 in patients with advanced carcinoma of the cervix. Vaccine 27: 3975-3983, 2009.

152. Borysiewicz LK, Fiander A, Nimako M, Man S, Wilkinson GW, Westmoreland D, Evans AS, Adams M, Stacey SN, Boursnell ME, et al: A recombinant vaccinia virus encoding human papillomavirus types 16 and 18, E6 and E7 proteins as immunotherapy for cervical cancer. Lancet 347: 1523-1527, 1996.

153. Kaufmann AM, Stern PL, Rankin EM, Sommer H, Nuessler V, Schneider A, Adams M, Onon TS, Bauknecht T, Wagner U, et al: Safety and immunogenicity of TA-HPV, a recombinant vaccinia virus expressing modified human papillomavirus (HPV)-16 and HPV-18 E6 and E7 genes, in women with progressive cervical cancer. Clin Cancer Res 8: 3676-3685, 2002 
154. Baldwin PJ, van der Burg SH, Boswell CM, Offringa R, Hickling JK, Dobson J, Roberts JS, Latimer JA, Moseley RP, Coleman N, et al: Vaccinia-expressed human papillomavirus 16 and 18 e6 and e7 as a therapeutic vaccination for vulval and vaginal intraepithelial neoplasia. Clin Cancer Res 9: 5205-5213, 2003

155. Brun JL, Dalstein V, Leveque J, Mathevet P, Raulic P, Baldauf JJ, Scholl S, Huynh B, Douvier S, Riethmuller D, et al: Regression of high-grade cervical intraepithelial neoplasia with TG4001 targeted immunotherapy. Am J Obstet Gynecol 204: 169.e1-e8, 2011.

156. Rosales R,López-ContrerasM,RosalesC,Magallanes-MolinaJR, Gonzalez-Vergara R, Arroyo-Cazarez JM, Ricardez-Arenas A, Del Follo-Valencia A, Padilla-Arriaga S, Guerrero MV, et al: Regression of human papillomavirus intraepithelial lesions is induced by MVA E2 therapeutic vaccine. Hum Gene Ther 25: 1035-1049, 2014.

157. Gomez-Gutierrez JG, Elpek KG, Montes de Oca-Luna R, Shirwan H, Sam Zhou H and McMasters KM: Vaccination with an adenoviral vector expressing calreticulin-human papillomavirus 16 E7 fusion protein eradicates E7 expressing established tumors in mice. Cancer Immunol Immunother 56: 997-1007, 2007.

158. Kast WM, Brandt RM, Sidney J, Drijfhout JW, Kubo RT, Grey HM, Melief CJ and Sette A: Role of HLA-A motifs in identification of potential CTL epitopes in human papillomavirus type 16 E6 and E7 proteins. J Immunol 152: 3904-3912, 1994.

159. Kenter GG, Welters MJ, Valentijn AR, Lowik MJ, Berends-van der Meer DM, Vloon AP, Essahsah F, Fathers LM, Offringa R, Drijfhout JW, et al: Vaccination against HPV-16 oncoproteins for vulvar intraepithelial neoplasia. N Engl J Med 361: 1838-1847, 2009

160. de Vos van Steenwijk PJ, Ramwadhdoebe TH, Löwik MJ, van der Minne CE, Berends-van der Meer DM, Fathers LM, Valentijn AR, Oostendorp J, Fleuren GJ, Hellebrekers BW, et al: A placebo-controlled randomized HPV16 synthetic long-peptide vaccination study in women with high-grade cervical squamous intraepithelial lesions. Cancer Immunol Immunother 61: 1485-1492, 2012.

161. van Poelgeest MI, Welters MJ, van Esch EM, Stynenbosch LF, Kerpershoek G, van Persijn van Meerten EL, van den Hende M, Löwik MJ, Berends-van der Meer DM, Fathers LM, et al: HPV16 synthetic long peptide (HPV16-SLP) vaccination therapy of patients with advanced or recurrent HPV16-induced gynecological carcinoma, a phase II trial. J Transl Med 11: 88, 2013.

162. de Vos van Steenwijk PJ, van Poelgeest MI, Ramwadhdoebe TH, Löwik MJ, Berends-van der Meer DM, van der Minne CE, Loof NM, Stynenbosch LF, Fathers LM, Valentijn AR, et al: The long-term immune response after HPV16 peptide vaccination in women with low-grade pre-malignant disorders of the uterine cervix: A placebo-controlled phase II study. Cancer Immunol Immunother 63: 147-160, 2014.

163. Welters MJ, van der Sluis TC, van Meir H, Loof NM, van Ham VJ, van Duikeren S, Santegoets SJ, Arens R, de Kam ML, Cohen AF, et al: Vaccination during myeloid cell depletion by cancer chemotherapy fosters robust T cell responses. Sci Trans Med 8: 334ra52, 2016.

164. Coleman HN, Greenfield WW, Stratton SL, Vaughn R, Kieber A, Moerman-Herzog AM, Spencer HJ, Hitt WC, Quick CM, Hutchins LF, et al: Human papillomavirus type 16 viral load is decreased following a therapeutic vaccination. Cancer Immunol Immunother 65: 563-573, 2016.

165. Su JH, Wu A, Scotney E, Ma B, Monie A, Hung CF and Wu TC: Immunotherapy for cervical cancer: Research status and clinical potential. BioDrugs 24: 109-129, 2010.

166. de Jong A, O'Neill T, Khan AY, Kwappenberg KM, Chisholm SE, Whittle NR, Dobson JA, Jack LC, St Clair Roberts JA, Offringa R, et al: Enhancement of human papillomavirus (HPV) type 16 E6 and E7-specific T-cell immunity in healthy volunteers through vaccination with TA-CIN, an HPV16 L2E7E6 fusion protein vaccine. Vaccine 20: 3456-3464, 2002

167. Daayana S, Elkord E, Winters U, Pawlita M, Roden R, Stern PL and Kitchener HC: Phase II trial of imiquimod and HPV therapeutic vaccination in patients with vulval intraepithelial neoplasia. Br J Cancer 102: 1129-1136, 2010.

168. Van Damme P, Bouillette-Marussig M, Hens A, De Coster I, Depuydt C, Goubier A, Van Tendeloo V, Cools N, Goossens H, Hercend T, et al: GTL001, A therapeutic vaccine for women infected with human papillomavirus 16 or 18 and normal cervical cytology: Results of a phase I clinical trial. Clin Cancer Res 22: 3238-3248, 2016.
169. Granadillo M, Vallespi MG, Batte A, Mendoza O, Soria Y, Lugo VM and Torrens I: A novel fusion protein-based vaccine comprising a cell penetrating and immunostimulatory peptide linked to human papillomavirus (HPV) type 16 E7 antigen generates potent immunologic and anti-tumor responses in mice. Vaccine 29: 920-930, 2011.

170. Vallespi MG, Glaria LA, Reyes O, Garay HE, Ferrero J and Araña MJ: A Limulus antilipopolysaccharide factor-derived peptide exhibits a new immunological activity with potential applicability in infectious diseases. Clin Diagn Lab Immunol 7: 669-675, 2000.

171. Lin KH, Chang LS, Tian CY, Yeh YC, Chen YJ, Chuang TH, Liu SJ and Leng CH: Carboxyl-terminal fusion of E7 into Flagellin shifts TLR5 activation to NLRC4/NAIP5 activation and induces TLR5-independent anti-tumor immunity. Sci Rep 6: 24199, 2016.

172. Lee SJ, Yang A, Wu TC and Hung CF: Immunotherapy for human papillomavirus-associated disease and cervical cancer: Review of clinical and translational research. J Gynecol Oncol 27: e51, 2016.

173. Vici P, Pizzuti L, Mariani L, Zampa G, Santini D, Di Lauro L, Gamucci T, Natoli C, Marchetti P, Barba M, et al: Targeting immune response with therapeutic vaccines in premalignant lesions and cervical cancer: Hope or reality from clinical studies. Expert Rev Vaccines 15: 1327-1336, 2016.

174. Yang A, Farmer E, Wu TC and Hung CF: Perspectives for therapeutic HPV vaccine development. J Biomed Sci 23: 75, 2016

175. Trimble C, Lin CT, Hung CF, Pai S, Juang J, He L, Gillison M, Pardoll D, Wu L and Wu TC: Comparison of the CD8+ T cell responses and antitumor effects generated by DNA vaccine administered through gene gun, biojector, and syringe. Vaccine 21: 4036-4042, 2003.

176. Best SR, Peng S, Juang CM, Hung CF, Hannaman D, Saunders JR, Wu TC and Pai SI: Administration of HPV DNA vaccine via electroporation elicits the strongest CD8+ T cell immune responses compared to intramuscular injection and intradermal gene gun delivery. Vaccine 27: 5450-5459, 2009.

177. Tsen SW, Wu CY, Meneshian A, Pai SI, Hung CF and Wu TC: Femtosecond laser treatment enhances DNA transfection efficiency in vivo. J Biomed Sci 16: 36, 2009.

178. Klencke B, Matijevic M, Urban RG, Lathey JL, Hedley ML, Berry M, Thatcher J, Weinberg V, Wilson J, Darragh T, et al: Encapsulated plasmid DNA treatment for human papillomavirus 16-associated anal dysplasia: A Phase I study of ZYC101. Clin Cancer Res 8: 1028-1037, 2002.

179. Hung CF, Hsu KF, Cheng WF, Chai CY, He L, Ling M and Wu TC: Enhancement of DNA vaccine potency by linkage of antigen gene to a gene encoding the extracellular domain of Fms-like tyrosine kinase 3-ligand. Cancer Res 61: 1080-1088, 2001.

180. Hauser H and Chen SY: Augmentation of DNA vaccine potency through secretory heat shock protein-mediated antigen targeting. Methods 31: 225-231, 2003.

181. Cheung YK, Cheng SC, Sin FW and Xie Y: Plasmid encoding papillomavirus Type 16 (HPV16) DNA constructed with codon optimization improved the immunogenicity against HPV infection. Vaccine 23: 629-638, 2004

182. Liu W, Gao F, Zhao KN, Zhao W, Fernando GJ, Thomas R and Frazer IH: Codon modified human papillomavirus type 16 E7 DNA vaccine enhances cytotoxic T-lymphocyte induction and anti-tumour activity. Virology 301: 43-52, 2002.

183. Lin CT, Tsai YC, He L, Calizo R, Chou HH, Chang TC, Soong YK, Hung CF and Lai CH: A DNA vaccine encoding a codon-optimized human papillomavirus type 16 E6 gene enhances CTL response and anti-tumor activity. J Biomed Sci 13: 481-488, 2006.

184. Smahel M, Poláková I, Pokorná D, Ludvíková V, Dusková M and Vlasák J: Enhancement of T cell-mediated and humoral immunity of beta-glucuronidase-based DNA vaccines against HPV16 E7 oncoprotein. Int J Oncol 33: 93-101, 2008.

185. Massa S, Simeone P, Muller A, Benvenuto E, Venuti A and Franconi R: Antitumor activity of DNA vaccines based on the human papillomavirus-16 E7 protein genetically fused to a plant virus coat protein. Hum Gene Ther 19: 354-364, 2008.

186. Chen CH, Wang TL, Hung CF, Yang Y, Young RA, Pardoll DM and Wu TC: Enhancement of DNA vaccine potency by linkage of antigen gene to an HSP70 gene. Cancer Res 60: 1035-1042, 2000.

187. Cheng WF, Hung CF, Chai CY, Hsu KF, He L, Ling M and Wu TC: Tumor-specific immunity and antiangiogenesis generated by a DNA vaccine encoding calreticulin linked to a tumor antigen. J Clin Invest 108: 669-678, 2001.

188. Bolhassani A,Zahedifard F, Taghikhani M and Rafati S: Enhanced immunogenicity of HPV16E7 accompanied by Gp96 as an adjuvant in two vaccination strategies. Vaccine 26: 3362-3370, 2008. 
189. Hung CF, Cheng WF, Hsu KF, Chai CY, He L, Ling M and Wu TC: Cancer immunotherapy using a DNA vaccine encoding the translocation domain of a bacterial toxin linked to a tumor antigen. Cancer Res 61: 3698-3703, 2001.

190.Hung CF, Cheng WF, He L, Ling M, Juang J, Lin CT and Wu TC: Enhancing major histocompatibility complex class I antigen presentation by targeting antigen to centrosomes. Cancer Res 63: 2393-2398, 2003.

191. Huang CH, Peng S, He L, Tsai YC, Boyd DA, Hansen TH, Wu TC and Hung $\mathrm{CF}$ : Cancer immunotherapy using a DNA vaccine encoding a single-chain trimer of MHC class I linked to an HPV-16 E6 immunodominant CTL epitope. Gene Ther 12: 1180-1186, 2005

192. Kim TW, Hung CF, Boyd D, Juang J, He L, Kim JW, Hardwick JM and $\mathrm{Wu}$ TC: Enhancing DNA vaccine potency by combining a strategy to prolong dendritic cell life with intracellular targeting strategies. J Immunol 171: 2970-2976, 2003.

193. Kim TW, Lee JH, He L, Boyd DA, Hardwick JM, Hung CF and Wu TC: Modification of professional antigen-presenting cells with small interfering RNA in vivo to enhance cancer vaccine potency. Cancer Res 65: 309-316, 2005.

194. Huang B, Mao CP, Peng S, Hung CF and Wu TC: RNA interference-mediated in vivo silencing of fas ligand as a strategy for the enhancement of DNA vaccine potency. Hum Gene Ther 19: 763-773, 2008.

195. Trimble CL, Morrow MP, Kraynyak KA, Shen X, Dallas M, Yan J, Edwards L, Parker RL, Denny L, Giffear M, et al: Safety, efficacy, and immunogenicity of VGX-3100, a therapeutic synthetic DNA vaccine targeting human papillomavirus 16 and 18 E6 and E7 proteins for cervical intraepithelial neoplasia 2/3 A randomised, double-blind, placebo-controlled phase $2 \mathrm{~b}$ trial. Lancet 386: 2078-2088, 2015.

196. Kim TJ, Jin HT, Hur SY, Yang HG, Seo YB, Hong SR, Lee CW, Kim S, Woo JW, Park KS, et al: Clearance of persistent HPV infection and cervical lesion by therapeutic DNA vaccine in CIN3 patients. Nat Commun 5: 5317, 2014

197. Maldonado L, Teague JE, Morrow MP, Jotova I, Wu TC, Wang C, Desmarais C, Boyer JD, Tycko B, Robins HS, et al Intramuscular therapeutic vaccination targeting HPV16 induces $\mathrm{T}$ cell responses that localize in mucosal lesions. Sci Trans Med 6: 221ra13, 2014.

198. Alvarez RD, Huh WK, Bae S, Lamb LS Jr, Conner MG, Boyer J, Wang C, Hung CF, Sauter E, Paradis M, et al: A pilot study of pNGVL4a-CRT/E7(detox) for the treatment of patients with HPV16+ cervical intraepithelial neoplasia 2/3 (CIN2/3). Gynecol Oncol 140: 245-252, 2016.

199. Kim TW, Hung CF, Juang J, He L, Hardwick JM and Wu TC: Enhancement of suicidal DNA vaccine potency by delaying suicidal DNA-induced cell death. Gene Ther 11: 336-342, 2004

200. Varnavski AN, Young PR and Khromykh AA: Stable high-level expression of heterologous genes in vitro and in vivo by noncytopathic DNA-based Kunjin virus replicon vectors. J Virol 74 4394-4403, 2000.

201. Herd KA,HarveyT,Khromykh AA and Tindle RW: Recombinant Kunjin virus replicon vaccines induce protective T-cell immunity against human papillomavirus 16 E7-expressing tumour. Virology 319: 237-248, 2004.

202. Tillman BW, Hayes TL, DeGruijl TD, Douglas JT and Curiel DT: Adenoviral vectors targeted to CD40 enhance the efficacy of dendritic cell-based vaccination against human papillomavirus 16 -induced tumor cells in a murine model. Cancer Res 60 $5456-5463,2000$

203. Mackova J, Kutinova L, Hainz P, Krystofova J, Sroller V, Otahal P, Gabriel P and Nemeckova S: Adjuvant effect of dendritic cells transduced with recombinant vaccinia virus expressing HPV16-E7 is inhibited by co-expression of IL12. Int J Oncol 24: 1581-1588, 2004.

204. Wang TL, Ling M, Shih IM, Pham T, Pai SI, Lu Z, Kurman RJ, Pardoll DM and Wu TC: Intramuscular administration of E7-transfected dendritic cells generates the most potent E7-specific anti-tumor immunity. Gene Ther 7: 726-733, 2000.

205. Benencia F, Courreges MC and Coukos G: Whole tumor antigen vaccination using dendritic cells: Comparison of RNA electroporation and pulsing with UV-irradiated tumor cells. J Trans Med 6: 21, 2008.

206. Murakami M, Gurski KJ, Marincola FM, Ackland J and Steller MA: Induction of specific CD8+ T-lymphocyte responses using a human papillomavirus-16 E6/E7 fusion protein and autologous dendritic cells. Cancer Res 59: 1184-1187, 1999.
207. Peng S, Kim TW, Lee JH, Yang M, He L, Hung CF and Wu TC: Vaccination with dendritic cells transfected with BAK and BAX siRNA enhances antigen-specific immune responses by prolonging dendritic cell life. Hum Gene Ther 16: 584-593, 2005.

208. Kim JH, Kang TH, Noh KH, Bae HC, Kim SH, Yoo YD, Seong SY and Kim TW: Enhancement of dendritic cell-based vaccine potency by anti-apoptotic siRNAs targeting key pro-apoptotic proteins in cytotoxic CD8(+) T cell-mediated cell death. Immunol Lett 122: 58-67, 2009.

209. Adams M, Navabi H, Jasani B, Man S, Fiander A, Evans AS, Donninger $\mathrm{C}$ and Mason M: Dendritic cell (DC) based therapy for cervical cancer: Use of DC pulsed with tumour lysate and matured with a novel synthetic clinically non-toxic double stranded RNA analogue poly (I):poly (C(12)U) (Ampligen R). Vaccine 21: 787-790, 2003.

210. Ahn YH,Hong SO, Kim JH, Noh KH, Song KH, Lee YH, Jeon JH, Kim DW, Seo JH and Kim TW: The siRNA cocktail targeting interleukin 10 receptor and transforming growth factor- $\beta$ receptor on dendritic cells potentiates tumour antigen-specific CD8(+) T cell immunity. Clin Exp Immunol 181: 164-178, 2015.

211. Santin AD, Bellone S, Palmieri M, Ravaggi A, Romani C, Tassi R, Roman JJ, Burnett A, Pecorelli S and Cannon MJ HPV16/18 E7-pulsed dendritic cell vaccination in cervical cancer patients with recurrent disease refractory to standard treatment modalities. Gynecol Oncol 100: 469-478, 2006.

212. Santin AD, Bellone S, Palmieri M, Zanolini A, Ravaggi A, Siegel ER, Roman JJ, Pecorelli S and Cannon MJ: Human papillomavirus type 16 and 18 E7-pulsed dendritic cell vaccination of stage IB or IIA cervical cancer patients: A phase I escalating-dose trial. J Virol 82: 1968-1979, 2008.

213. Bubenik J, Símová J, Hájková R, Sobota V, Jandlová T, Smahel M, Sobotková E and Vonka V: Interleukin 2 gene therapy of residual disease in mice carrying tumours induced by HPV 16. Int J Oncol 14: 593-597, 1999.

214. Mikyskova R, Indrová M, Símová J, Jandlová T, Bieblová J, Jinoch P, Bubeník J and Vonka V: Treatment of minima residual disease after surgery or chemotherapy in mice carrying HPV16-associated tumours: Cytokine and gene therapy with IL-2 and GM-CSF. Int J Oncol 24: 161-167, 2004

215. Hallez S, Detremmerie O, Giannouli C, Thielemans K, Gajewski TF, Burny A and Leo O: Interleukin-12-secreting human papillomavirus type 16-transformed cells provide a potent cancer vaccine that generates E7-directed immunity. Int J Cancer 81: 428-437, 1999.

216. Chang EY, Chen CH, Ji H, Wang TL, Hung K, Lee BP, Huang AY, Kurman RJ, Pardoll DM and Wu T: Antigen-specific cancer immunotherapy using a GM-CSF secreting allogeneic tumor cell-based vaccine. Int J Cancer 86: 725-730, 2000.

217. Thompson PL and Dessureault S: Tumor cell vaccines. Adv Exp Med Biol 601: 345-355, 2007.

218. Stevanović S, Draper LM, Langhan MM, Campbell TE, Kwong ML, Wunderlich JR, Dudley ME, Yang JC, Sherry RM, Kammula US, et al: Complete regression of metastatic cervical cancer after treatment with human papillomavirus-targeted tumor-infiltrating T cells. J Clin Oncol 33: 1543-1550, 2015.

219. Draper LM, Kwong ML, Gros A, Stevanović S, Tran E, Kerkar S, Raffeld M, Rosenberg SA and Hinrichs CS: Targeting of HPV-16+ epithelial cancer cells by TCR gene engineered T cells directed against E6. Clin Cancer Res 21: 4431-4439, 2015

220. Beutner KR, Geisse JK, Helman D, Fox TL, Ginkel A and Owens ML: Therapeutic response of basal cell carcinoma to the immune response modifier imiquimod 5\% cream. J Am Acad Dermatol 41: 1002-1007, 1999

221. Buck HW and Guth KJ: Treatment of vaginal intraepithelial neoplasia (primarily low grade) with imiquimod $5 \%$ cream. J Low Genit Tract Dis 7: 290-293, 2003.

222. Terlou A, van Seters M, Ewing PC, Aaronson NK, Gundy CM, Heijmans-Antonissen C, Quint WG, Blok LJ, van Beurden M and Helmerhorst TJ: Treatment of vulvar intraepithelial neoplasia with topical imiquimod: Seven years median follow-up of a randomized clinical trial. Gynecol Oncol 121: 157-162, 2011.

223. Fox PA, Nathan M, Francis N, Singh N, Weir J, Dixon G, Barton SE and Bower M: A double-blind, randomized controlled trial of the use of imiquimod cream for the treatment of anal canal high-grade anal intraepithelial neoplasia in HIV-positive MSM on HAART, with long-term follow-up data including the use of open-label imiquimod. Aids 24: 2331-2335, 2010. 